This document is confidential and is proprietary to the American Chemical Society and its authors. Do not copy or disclose without written permission. If you have received this item in error, notify the sender and delete all copies.

\title{
ORIENTATIONAL EFFECTS AND RANDOM MIXING IN 1- ALKANOL + NITRILE MIXTURES
}

\begin{tabular}{|r|l|}
\hline Journal: & Industrial \& Engineering Chemistry Research \\
\hline Manuscript ID: & ie-2014-04282s.R1 \\
\hline Manuscript Type: & Article \\
\hline Date Submitted by the Author: & $10-$ Dec-2014 \\
\hline Complete List of Authors: & $\begin{array}{l}\text { Gonzalez, Juan; University of Valladolid, Física Aplicada } \\
\text { García de la Fuente, Isaias; UNiveridad de Valladolid, Física Aplicada } \\
\text { Cobos, Jose; Universidad de Valladolid, Dpto Termodinamica y Fisica } \\
\text { Aplicada } \\
\text { Alonso-Tristán, Cristina; UNIVERSITY OF BURGOS, INGENIERÍA } \\
\text { ELECTROMECÁNICA } \\
\text { Sanz, Luis; Universidad de Valladolid, Física Aplicada }\end{array}$ \\
\hline
\end{tabular}

\section{SCHOLARONE ${ }^{\text {Th }}$}

Manuscripts 


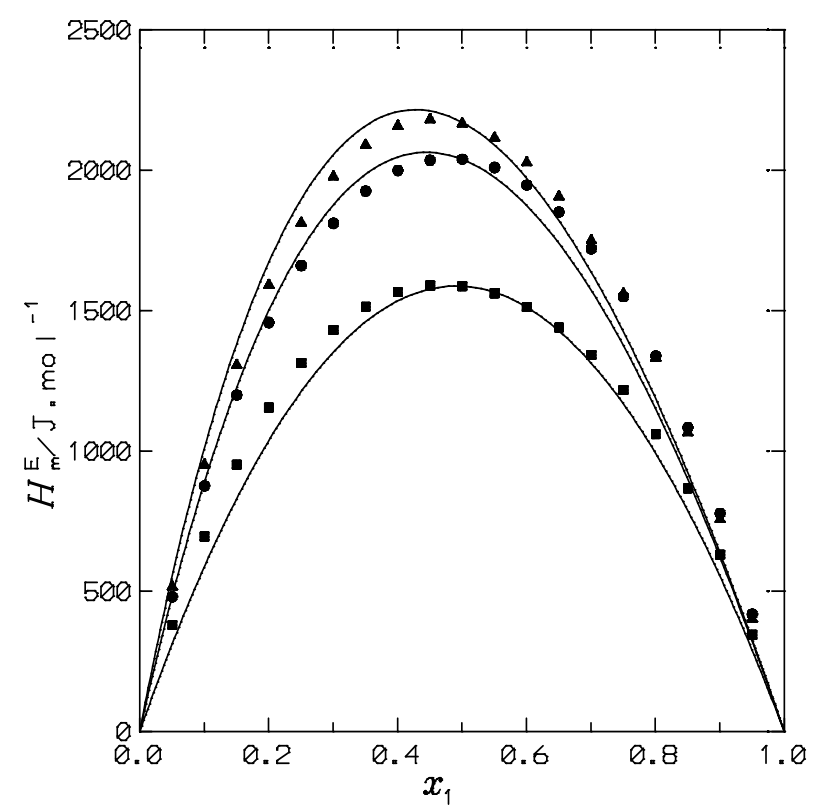

$H_{\mathrm{m}}^{\mathrm{E}}$ at $29815 \mathrm{~K}$ for 1-butanol(1) + ethanenitrile(2) (•), or + butanenitrile(2) ( $)$ ), or for 1decanol(1) + butanenitrile(2) (•). Solid lines, Flory calculations 


\title{
ORIENTATIONAL EFFECTS AND RANDOM MIXING IN 1-ALKANOL + NITRILE MIXTURES
}

\author{
JUAN ANTONIO GONZÁLEZ ${ }^{(1)^{*}}$, ISAÍAS GARCÍA DE LA FUENTEE ${ }^{(1)}$, JOSÉ CARLOS \\ $\operatorname{COBOS}^{(1)}$, CRISTINA ALONSO TRISTÁN ${ }^{(2)}$ AND LUIS F. SANZ ${ }^{(1)}$
}

(1) G.E.T.E.F., Departamento de Física Aplicada, Facultad de Ciencias, Universidad de Valladolid, Paseo de Belén, 7, 47011 Valladolid, Spain,

*e-mail: jagl@termo.uva.es; Fax: +34-983-423136; Tel: +34-983-423757

${ }^{(2)}$ Dpto. Ingeniería Electromecánica. Escuela Politécnica Superior. Avda. Cantabria s/n. 09006 Burgos, (Spain) 


\section{Abstract}

1-Alkanol + alkanenitrile, or + benzonitrile systems have been investigated by means of the molar excess functions: enthalpies $\left(H_{\mathrm{m}}^{\mathrm{E}}\right)$, isobaric heat capacities $\left(C_{\mathrm{pm}}^{\mathrm{E}}\right)$, volumes $\left(V_{\mathrm{m}}^{\mathrm{E}}\right)$ and entropies, and using the Flory model and the concentration-concentration structure factor $\left(S_{\mathrm{CC}}(0)\right)$ formalism. From the analysis of the experimental data available in the literature, it is concluded that interactions are mainly of dipolar type. In addition, large $H_{\mathrm{m}}^{\mathrm{E}}$ values contrast with rather low $V_{\mathrm{m}}^{\mathrm{E}}$ values, indicating the existence of strong structural effects. $H_{\mathrm{m}}^{\mathrm{E}}$ measurements have been used to evaluate the enthalpy of the hydroxyl-nitrile interactions $\left(\Delta H_{\mathrm{OH}-\mathrm{CN}}\right)$. They are stronger in methanol systems and become weaker when the alcohol size increases. In solutions with a given short chain 1-alkanol (up to 1-butanol), the replacement of ethanenitrile by butanenitrile weakens the mentioned interactions. Application of the Flory model shows that orientational effects exist in methanol or 1-nonanol, or 1-decanol + ethanenitrile mixtures. In the former solution, this is due to the existence of interactions between unlike molecules. For mixtures including 1-nonanol or 1-decanol, the systems at $298.15 \mathrm{~K}$ are close to their UCST (upper critical solution temperature), and interactions between like molecules are dominant. Orientational effects also are encountered in methanol or ethanol + butanenitrile mixtures due to self-association of the alcohol plays a more important role. Aromaticity effect seems to enhance orientational effects. For the remainder systems under consideration, the random mixing hypothesis is attained in rather large extent. Results from the application of the $S_{\mathrm{CC}}(0)$ formalism shows that homocoordination is the dominant trend in the investigated solutions, and are consistent with those obtained from the Flory model.

KEYWORDS: 1-alkanols/ nitriles/ excess functions/ dipolar interactions/ structural effects/ random mixing. 


\section{Introduction}

Nitriles show a large variety of applications in synthesis of plastics, cosmetics, pharmaceuticals and of other organic chemicals. They are also important as hydrogen bond acceptors. ${ }^{1-3}$ Interestingly, aqueous solutions of acetonitrile are used for the separation of protein and peptides mixtures. ${ }^{4}$

1-Alkanol + nitrile mixtures have been studied in terms of different theories. Systems with methanol, ethanol, 1-propanol or 1-butanol and acetonitrile have been investigated by means of an association model which assumes the existence of linear and cyclic species for alcohols and acetonitrile, and only open chains for alcohol-nitrile heterocomplexes. ${ }^{5-7}$ In this theory, the physical contribution to the molar excess enthalpy, $H_{\mathrm{m}}^{\mathrm{E}}$. is derived from the NRTL equation..$^{5-7}$ The model yields an accurate representation for $H_{\mathrm{m}}^{\mathrm{E}}$ of the mentioned binary systems and, neglecting ternary interactions, for related ternary solutions including benzene as third component. ${ }^{5-7}$ The UNIQUAC association solution model has been also used for the study of the same binary solutions cited above. $^{8-10}$ In this case, the physical contribution to $H_{\mathrm{m}}^{\mathrm{E}}$ is obtained from the UNIQUAC equation, ${ }^{8-}$ ${ }^{10}$ and only linear polymers for self-association of 1-alcohols and for alcohol-nitrile solvation are taken into account. ${ }^{8-10}$ The well-known ERAS model ${ }^{11}$ and the Flory-Benson-Treszczanowicz theory ${ }^{12}$ have been applied to some 1-alkanol + ethanenitrile, + propanenitrile, + butanenitrile or + benzonitrile mixtures. ${ }^{13-17}$

In a series of works, we have shown that the Flory model ${ }^{18}$ is an useful tool to investigate the existence of orientational effects in liquid mixtures. Systems of the type: 1-alkanol + linear or cyclic monoether, ${ }^{19}+$ linear polyether, ${ }^{20}$ or + alkanone, ${ }^{21}$ or 1-butanol + alkoxyethanol, ${ }^{22}$ or ether + alkane, ${ }^{23}+$ benzene, or + toluene, ${ }^{24}$ or $+\mathrm{CCl}_{4}{ }^{25}$ have been investigated using this approach. As continuation, we now pay attention to orientational effects in 1-alkanol + nitrile mixtures by means of the same methodology. As far as we know, only molar excess volumes, $V_{\mathrm{m}}^{\mathrm{E}}$, of 1-alkanol + ethanenitrile systems ${ }^{26}$ have been correlated by means of the Prigogine-Flory-Patterson model. ${ }^{18,27}$

On the other hand, it is interesting to link thermodynamic properties of liquid mixtures with local deviations from the bulk composition. The investigation of fluctuations in a binary system $^{28-30}$ can be conducted in terms of so-called Kirkwood-Buff integrals formalism ${ }^{31,32}$ where fluctuations in the number of molecules of each component and the cross fluctuations are taken into account. A different alternative, due to Bhatia and Thorton, ${ }^{33}$ is concerned with the study of fluctuations in the number of molecules regardless of the components, the fluctuations in the mole fraction and the cross fluctuations. This approach has been used in the investigation of liquid binary alloys. ${ }^{34,35}$ We have applied it to mixtures involving pyridines ${ }^{36}$ or to 1 -alkanol + cyclic ether, ${ }^{37}+$ aromatic hydrocarbon $^{38}$ or + alkanone $^{21}$ systems and here is extended to 1 alkanol + nitrile solutions. 


\section{Theories}

\subsubsection{Flory model}

The main hypotheses of the theory ${ }^{18,39-42}$ have been summarized elsewhere ${ }^{21,23}$ and will not be repeated here. We merely remark that random mixing is a basic assumption of the model. The Flory equation of state is:

$$
\frac{\bar{P} \bar{V}}{\bar{T}}=\frac{\bar{V}^{1 / 3}}{\bar{V}^{1 / 3}-1}-\frac{1}{\bar{V} \bar{T}}
$$

where $\bar{V}=V / V^{*} ; \bar{P}=P / P^{*}$ and $\bar{T}=T / T^{*}$ are the reduced volume, pressure and temperature, respectively. Equation (1) is valid for pure liquids and liquid mixtures. For pure liquids, the reduction parameters, $V_{i}^{*}, P_{i}^{*}$ and $T_{i}^{*}$ are obtained from densities, $\rho_{\mathrm{i}}$, isobaric thermal expansion coefficients, $\alpha_{\mathrm{Pi}}$, and isothermal compressibilities, $\kappa_{\mathrm{Ti}}$, data. Expressions for reduction parameters of mixtures are given elsewhere. ${ }^{23} H_{\mathrm{m}}^{\mathrm{E}}$ is determined from:

$$
H_{\mathrm{m}}^{\mathrm{E}}=\frac{x_{1} V_{1}^{*} \theta_{2} X_{12}}{\bar{V}}+x_{1} V_{1}^{*} P_{1}^{*}\left(\frac{1}{\bar{V}_{1}}-\frac{1}{\bar{V}}\right)+x_{2} V_{2}^{*} P_{2}^{*}\left(\frac{1}{\bar{V}_{2}}-\frac{1}{\bar{V}}\right)
$$

where all the symbols have their usual meaning. ${ }^{23}$ In equation (2), the term which depends directly on $X_{12}$ is commonly named the interaction contribution to $H_{\mathrm{m}}^{\mathrm{E}}$. The remaining terms are the so-called equation of state contribution to $H_{\mathrm{m}}^{\mathrm{E}}$. The reduced volume of the mixture, $\bar{V}$, in equation (2) is obtained from (1). Therefore, the molar excess volume can be also calculated:

$$
V_{\mathrm{m}}^{\mathrm{E}}=\left(x_{1} V_{1}^{*}+x_{2} V_{2}^{*}\right)\left(\bar{V}-\varphi_{1} \bar{V}_{1}-\varphi_{2} \bar{V}_{2}\right)
$$

\subsubsection{Estimation of the Flory interaction parameter}

$X_{12}$ is determined from a $H_{\mathrm{m}}^{\mathrm{E}}$ measurement at given composition from: ${ }^{19,21,22}$

$$
X_{12}=\frac{x_{1} P_{1}^{*} V_{1}^{*}\left(1-\frac{\bar{T}}{\bar{T}}\right)+x_{2} P_{2}^{*} V_{2}^{*}\left(1-\frac{\bar{T}_{2}}{\bar{T}}\right)}{x_{1} V_{1}^{*} \theta_{2}}
$$

For the application of this expression, we note that $\bar{V} \bar{T}$ is a function of $H_{\mathrm{m}}^{\mathrm{E}}$ :

$$
H_{\mathrm{m}}^{\mathrm{E}}=\frac{x_{1} P_{1}^{*} V_{1}^{*}}{\bar{V}_{1}}+\frac{x_{2} P_{2}^{*} V_{2}^{*}}{\bar{V}_{2}}+\frac{1}{\bar{V} \bar{T}}\left(x_{1} P_{1}^{*} V_{1}^{*} \bar{T}_{1}+x_{2} P_{2}^{*} V_{2}^{*} \bar{T}_{2}\right)
$$


and that from the equation of state, $\bar{V}=\bar{V}(\bar{T})$. More details can be found elsewhere. ${ }^{19,22,23}$ Equation (5) is a generalization of that previously given to calculate $X_{12}$ from $H_{\mathrm{m}}^{\mathrm{E}}$ at $x_{1}=$ $0.5{ }^{43}$ Properties of nitriles $(i=2)$ at $298.15 \mathrm{~K}$, molar volumes, $V_{\mathrm{i}}, \alpha_{P i}, \kappa_{T i}$, and the corresponding reduction parameters, $P_{i}^{*}$ and $V_{i}^{*}$, needed for calculations are listed in Table 1. For 1 -alkanols $(i=1)$, values have been taken from the literature. ${ }^{20}$ At $T \neq 298.15 \mathrm{~K}$, the mentioned properties were estimated using the same equations as in previous applications for the temperature dependence of $\rho, \alpha_{\mathrm{p}}$ and $\gamma\left(=\alpha_{p} / \kappa_{T}\right) \cdot{ }^{19,44} X_{12}$ values determined from experimental $H_{\mathrm{m}}^{\mathrm{E}}$ data at $x_{1}=0.5$ are collected in Table 2.

\subsection{The concentration-concentration structure factor}

Mixture structure can be studied using the $S_{\mathrm{CC}}(0)$ function ${ }^{21,29,30,45}$

$$
S_{\mathrm{CC}}(0)=\frac{R T}{\left(\partial^{2} G^{\mathrm{M}} / \partial x_{1}^{2}\right)_{P, T}}=\frac{x_{1} x_{2}}{D}
$$

with

$$
D=\frac{x_{1} x_{2}}{R T}\left(\partial^{2} G^{\mathrm{M}} / \partial x_{1}^{2}\right)_{P, T}=1+\frac{x_{1} x_{2}}{R T}\left(\frac{\partial^{2} G_{\mathrm{m}}^{\mathrm{E}}}{\partial x_{1}^{2}}\right)_{P, T}
$$

In equations (6) and (7), $G^{\mathrm{M}}, G_{\mathrm{m}}^{\mathrm{E}}$ are the molar Gibbs energy of mixing and the molar excess Gibbs energy, respectively. $D$ is a function closely related to thermodynamic stability. ${ }^{46-48}$ For ideal mixtures, $G_{\mathrm{m}}^{\mathrm{E} \text {,id }}=0 ; D^{\mathrm{id}}=1$ and $S_{\mathrm{CC}}(0)=x_{1} x_{2}$. Stability conditions require that $S_{\mathrm{CC}}(0)>$ 0 . Then, for a system close to phase separation, $S_{\mathrm{CC}}(0)$ must be large and positive ( $\infty$, when there is inmiscibility). If compound formation between components appears, $S_{\mathrm{CC}}(0)$ must be very low $\left(0\right.$, in the limit). Therefore, $S_{\mathrm{CC}}(0)>x_{1} x_{2}(D<1)$ implies that the dominant trend in the system is the homocoordination (separation of the components), and the mixture is less stable than the ideal. If $0<S_{\mathrm{CC}}(0)<x_{1} x_{2}=S_{\mathrm{CC}}(0)^{\text {id }},(D>1)$, the fluctuations in the system have been removed, and the dominant trend in the solution is heterocoordination (compound formation). In such case, the system is more stable than ideal. In summary, $S_{\mathrm{CC}}(0)$ is an useful magnitude to evaluate the non-randomness in the mixture..$^{30,45}$ 


\section{Results}

Results on $H_{\mathrm{m}}^{\mathrm{E}}$ obtained from the Flory model using $X_{12}$ values at $x_{1}=0.5$ are listed in Table 2, which also contains the interactional contribution to $H_{\mathrm{m}}^{\mathrm{E}}$ at equimolar composition and, for the sake of clarity, the relative standard deviations for $H_{\mathrm{m}}^{\mathrm{E}}$ calculated according to:

$$
\sigma_{r}\left(H_{\mathrm{m}}^{\mathrm{E}}\right)=\left[\frac{1}{N} \sum\left(\frac{H_{\mathrm{m}, \text { exp }}^{\mathrm{E}}-H_{\mathrm{m}, \text { calc }}^{\mathrm{E}}}{H_{\mathrm{m}, \exp }^{\mathrm{E}}}\right)^{2}\right]^{1 / 2}
$$

where $N(=19)$ is the number of data points, and $H_{\mathrm{m} \text {,exp }}^{\mathrm{E}}$ stands for the smoothed $H_{\mathrm{m}}^{\mathrm{E}}$ values calculated at $\Delta x_{1}=0.05$ in the composition range [0.05, 0.95] from polynomial expansions, previously checked, given in the original works (see Table 2). A graphical comparison between experimental and theoretical $H_{\mathrm{m}}^{\mathrm{E}}$ values are shown in Figures 1 and 2. The concentration dependence of $X_{12}$, according to equation (4) is shown in Figure 3 for some selected systems. Table 3 lists the results obtained for the $S_{\mathrm{CC}}(0)$ function (see also Figure 4 ). $D$ values were calculated from $G_{\mathrm{m}}^{\mathrm{E}}$ functions represented by means of equations of the Redlich-Kister type with parameters determined from isothermal vapour-liquid equilibria available in the literature.

\section{Discussion}

Along this section, we are referring to the excess functions at equimolar composition and $298.15 \mathrm{~K}$. On the other hand, $n_{\mathrm{OH}}$ stands for the number of $\mathrm{C}$ atoms of the 1-alkanol, and $n_{\mathrm{CN}}$ represents the number of $\mathrm{C}$ atoms of the alkyl chain attached to the $\mathrm{CN}$ group.

\subsection{Enthalpies of the hydroxyl-nitrile interactions}

If structural effects are neglected, ${ }^{46,49} H_{\mathrm{m}}^{\mathrm{E}}$ can be considered as the result of three contributions. $\Delta H_{\mathrm{OH}-\mathrm{OH}}, \Delta H_{\mathrm{CN}-\mathrm{CN}}$ are positive contributions and arise, respectively, from the disruption of alkanol-alkanol and nitrile-nitrile interactions during the mixing process; $\Delta H_{\mathrm{OH}-\mathrm{CN}}$ is a negative term related to the new $\mathrm{OH}---\mathrm{CN}$ interactions created upon that process. Therefore: ${ }^{50-53}$

$$
H_{\mathrm{m}}^{\mathrm{E}}=\Delta H_{\mathrm{OH}-\mathrm{OH}}+\Delta H_{\mathrm{CN}-\mathrm{CN}}+\Delta H_{\mathrm{OH}-\mathrm{CN}}
$$


The $\Delta H_{\text {OH-CN }}$ term represents the enthalpy of the H-bonds between 1-alkanols and nitriles. This magnitude can be evaluated by extending the equation (9) to $x_{1} \rightarrow 0,{ }^{53-56}$ and replacing, $\Delta H_{\mathrm{OH}-\mathrm{OH}}$ and $\Delta H_{\mathrm{CN}-\mathrm{CN}}$ by the corresponding $H_{\mathrm{m} 1}^{\mathrm{E}, \infty}$ values (partial excess molar enthalpy at infinite dilution of the first component) of 1-alkanol or nitrile + alkane systems. Thus,

$$
\begin{aligned}
& \Delta H_{\mathrm{OH}-\mathrm{CN}}=H_{\mathrm{m} 1}^{\mathrm{E}, \infty}(1-\text { alkanol }+ \text { nitrile }) \\
& -H_{\mathrm{m} 1}^{\mathrm{E}, \infty}(1-\text { alkanol }+ \text { alkane })-H_{\mathrm{m} 1}^{\mathrm{E}, \infty}(\text { nitrile + alkane })
\end{aligned}
$$

This procedure shows some shortcomings: (i) for 1-alkanol + nitrile systems, the $H_{\mathrm{ml}}^{\mathrm{E}, \infty}$ data used were often calculated from $H_{\mathrm{m}}^{\mathrm{E}}$ measurements over the entire mole fraction range. Nevertheless, we note that there is a fair agreement between such data and those obtained from calorimetric measurements at high dilution of the 1 -alkanol ${ }^{57}$ (Table 4) (ii) For 1-alkanol + alkane systems, it was assumed that $H_{\mathrm{m} 1}^{\mathrm{E}, \infty}$ is independent of the alcohol, a common approach when applying association theories. ${ }^{11,58-60}$ As in previous applications, ${ }^{20,21,53}$ we have used

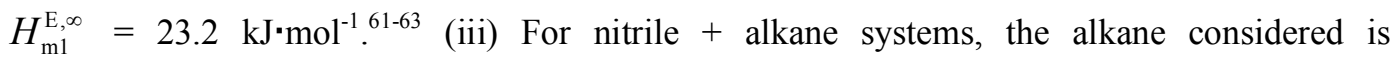
cyclohexane as $H_{\mathrm{m} 1}^{\mathrm{E}, \infty}$ data are available in the literature for these solutions. ${ }^{57}$ The $\Delta H_{\mathrm{OH}-\mathrm{CN}}$ values obtained are listed in Table 4 (Fig. 5). From their inspection, some statements can be outlined. (i) For mixtures including a given nitrile, $\Delta H_{\mathrm{OH}-\mathrm{CN}}$ increases with $n_{\mathrm{OH}}$, which indicates that alcohol-nitrile interactions become then weaker. (ii) Interestingly, such $\Delta H_{\mathrm{OH}-\mathrm{CN}}$ variation is sharper for solutions with $n_{\mathrm{CN}}=1$, than for those with $n_{\mathrm{CN}}=3$ (Figure 5). This may be ascribed to the fact that 1-octanol, or 1-decanol or 1-undecanol + ethanenitrile mixtures show miscibility gaps at temperatures close to $298.15 \mathrm{~K}$ at the composition range $(0,0.7)$ of the alcohol, while systems with butanenitrile do not show this behaviour. ${ }^{13,64}$ The coordinates $\left(x_{1 \mathrm{c}}, T_{\mathrm{c}} / \mathrm{K}\right)$ of the critical points for acetonitrile mixtures are: ${ }^{13}$ (0.266, 282.08) (1-octanol); (0.252, 297.06) (1-decanol); (0.216, 303.26) (1-undecanol). Therefore, $H_{\mathrm{m}}^{\mathrm{E}}$ values of the mixtures with 1-nonanol or 1-decanol are very large and positive (Table 2), ${ }^{14}$ which remarks that interactions between like molecules are preponderant in such solutions. (iii) Interactions between unlike molecules are stronger in mixtures with $n_{\mathrm{OH}}=1-4$ and $n_{\mathrm{CN}}=1$. (Table 4, Fig. 5). (iv) There are no relevant differences between $\Delta H_{\mathrm{OH}-\mathrm{CN}}$ values for systems with butanenitrile or benzonitrile. 
The $\Delta H_{\mathrm{OH}-\mathrm{CN}}$ values reported in the literature depend on the method applied for their estimation. In the UNIQUAC associated solution model, the value $-17.0 \mathrm{~kJ} \cdot \mathrm{mol}^{-1}$ is used for the mixtures methanol, ethanol, or 1-propanol + ethanenitrile. ${ }^{8-10}$ In the association model with a physical term represented by the NRTL equation, solvation between alcohols and ethanenitrile molecules are considered to be of the type $\mathrm{A}_{\mathrm{i}} \mathrm{B}$ and $\mathrm{A}_{\mathrm{i}} \mathrm{B}_{\mathrm{j}}(\mathrm{A}=$ alcohol; $\mathrm{B}=$ nitrile $)$ and the corresponding enthalpies are -22 and $-16.8 \mathrm{~kJ} \cdot \mathrm{mol}^{-1}$,-7 respectively. In the framework of the ERAS model, the following values of $\Delta h_{\mathrm{AB}}^{*}$ (enthalpy of solvation) have been reported for 1alkanol + butanenitrile mixtures: ${ }^{15}-8.9$ (methanol); -1.0 (ethanol); -16.5 (1-propanol) $\mathrm{kJ} \cdot \mathrm{mol}^{-1}$. For ethanenitrile systems, $\left.\Delta h_{\mathrm{AB}}^{*} / \mathrm{kJ} \cdot \mathrm{mol}^{-1}\right)=-17.15$ (1-nonanol); - 17 (1-decanol). ${ }^{14}$ Infrared spectroscopy studies provide for the enthalpy of hydrogen bonding for alcohols with nitriles (all values in $\left.\mathrm{kJ} \cdot \mathrm{mol}^{-1}\right):^{65}-10.88$ (methanol + ethanenitrile); -8.37 (1-butanol + ethanenitrile); - 10.05 (methanol + butanenitrile); -7.12 (1-butanol + butanennitrile); - 8.79 (methanol + benzenitrile); -6.69 (1-butanol + benzenenitrile).

\subsection{Excess molar enthalpies and excess molar entropies.}

$H_{\mathrm{m}}^{\mathrm{E}}$ values of 1-alkanol + nitrile mixtures are large and positive (Table 2). Therefore, the main contributions to this excess function arise from the breaking of the interactions between like molecules. This means that the $\Delta H_{\mathrm{OH}-\mathrm{OH}}, \Delta H_{\mathrm{CN}-\mathrm{CN}}$ terms in equation 9 are higher than $\left|\Delta H_{\mathrm{OH}-\mathrm{CN}}\right|$. Except for methanol solutions, $H_{\mathrm{m}}^{\mathrm{E}}(1$-alkanol + nitrile $)>H_{\mathrm{m}}^{\mathrm{E}}(1$-alkanol + isomeric hydrocarbon). Thus, $H_{\mathrm{m}}^{\mathrm{E}}(1-$ propanol $) / \mathrm{J} \cdot \mathrm{mol}^{-1}=1587\left(n_{\mathrm{CN}}=3\right)^{66}>459$ (pentane) ${ }^{67}$ 1454 (benzonitrile) ${ }^{15}>880$ (toluene) ${ }^{68}$ This clearly reveals that nitriles are good breakers of the alcohol self-association. The fact that the Kirkwood correlation factor of methanol + alkanenitrile mixtures does not show a minimum at low alcohol concentrations ${ }^{69}$ supports our conclusion. The existence of such minimum is characteristic of 1-alkanol + alkane mixtures and is ascribed to the existence of cyclic species, mainly tetramers, at the mentioned low concentrations of alcohol. ${ }^{70,71}$ The replacement of alkane by a nitrile leads to the breaking of the cyclic species and, consequently, the minimum vanishes. Many solutions behave similarly. ${ }^{70,72}$ On the other hand, in mixtures involving a given nitrile, $H_{\mathrm{m}}^{\mathrm{E}}$ increases with $n_{\mathrm{OH}}$ and the $H_{\mathrm{m}}^{\mathrm{E}}$ curves are rather symmetrical, except for mixtures containing methanol (Figures 1-2). These features indicate that interactions are essentially of dipolar type and effects related to selfassociation of 1-alkanols and to solvation between unlike molecules are here of minor importance. Systems where self-association of alcohols plays the dominant role, as 1-alkanol + heptane, are characterized by the following features: (i) $H_{\mathrm{m}}^{\mathrm{E}}$ increases from ethanol to 1propanol or 1-butanol and then smoothly decreases; (ii) the $H_{\mathrm{m}}^{\mathrm{E}}$ curves are shifted to low mole 
fractions of the alcohol, ${ }^{53}$ and the corresponding $H_{\mathrm{m}}^{\mathrm{E}}$ values are rather low (see above); (iii) the isobaric excess heat capacities, $C_{\mathrm{p}, \mathrm{m}}^{\mathrm{E}}$, are large and positive $\left(11.7 \mathrm{~J} \cdot \mathrm{mol}^{-1} \cdot \mathrm{K}^{-1}\right.$ for ethanol + heptane $\left.{ }^{73}\right)$; (iv) in contrast, values of $T S_{\mathrm{m}}^{\mathrm{E}}\left(=H_{\mathrm{m}}^{\mathrm{E}}-G_{\mathrm{m}}^{\mathrm{E}}\right)$ are large and negative. For the ethanol + hexane mixture, $H_{\mathrm{m}}^{\mathrm{E}}=548 ;^{74} G_{\mathrm{m}}^{\mathrm{E}}=1374^{62}$ and $T S_{\mathrm{m}}^{\mathrm{E}}=-826$ (data in $\left.\mathrm{J} \cdot \mathrm{mol}^{-1}\right)$. The corresponding values of $C_{\mathrm{p}, \mathrm{m}}^{\mathrm{E}}$ for 1-alkanol + nitrile mixtures are much lower, and those of $T S_{\mathrm{m}}^{\mathrm{E}}$ are positive (Table 3). Thus, $C_{\mathrm{p}, \mathrm{m}}^{\mathrm{E}}\left(n_{\mathrm{CN}}=1\right) / \mathrm{J} \cdot \mathrm{mol}^{-1} \cdot \mathrm{K}^{-1}$, estimated from $\frac{\Delta H_{m}^{E}}{\Delta T}$, is 5.3 and 7.4 for the methanol and ethanol solutions, respectively. ${ }^{5}$ All this supports the importance of dipolar interactions in the investigated systems.

\subsubsection{The effect of increasing $n_{\mathrm{CN}}$ in mixtures with a given 1-alcohol}

$H_{\mathrm{m}}^{\mathrm{E}}$ decreases at this condition, which can be ascribed to the following features. (i) Polarity of longer nitriles is weaker. As a consequence, the UCST, $T_{\mathrm{c}}$, decreases when $n_{\mathrm{CN}}$ increases in mixtures with a given alkane. For example, $T_{\mathrm{c}}$ (hexane) $/ \mathrm{K}=350.2\left(n_{\mathrm{CN}}=1\right)>$ $284.2\left(n_{\mathrm{CN}}=2\right)>244.2\left(n_{\mathrm{CN}}=3\right) .^{75}$ This leads to a lower $\Delta H_{\mathrm{CN}-\mathrm{CN}}$ contribution to $H_{\mathrm{m}}^{\mathrm{E}}$ when $n_{\mathrm{CN}}$ is increased (Table 4), effect which is predominant over: (ii) a larger $\Delta H_{\mathrm{OH}-\mathrm{OH}}$ term related to the higher number of alcohol-alcohol interactions broken by nitriles with larger aliphatic surfaces. It should be kept in mind that $H_{\mathrm{m}}^{\mathrm{E}}$ of 1 -alkanol $+n$-alkane mixtures increases with the alkane size. $^{76}$ (iii) A more negative $\Delta H_{\mathrm{OH}-\mathrm{CN}}$ contribution for mixtures with $n_{\mathrm{CN}}=1$ and particularly, $n_{\mathrm{OH}}=1-4$.

\subsubsection{The effect of increasing $n_{\mathrm{OH}}$ in systems with a given nitrile}

Now, $H_{\mathrm{m}}^{\mathrm{E}}$ increases (Table 2). This may be due to: (i) the weakening of the alcoholnitrile interactions (larger $\Delta H_{\mathrm{OH}-\mathrm{CN}}$ contribution, Table 4). (ii) Increased $\Delta H_{\mathrm{CN}-\mathrm{CN}}$ contribution, as it is expected that more nitrile-nitrile interactions are broken by alcohols with larger aliphatic surfaces. Note that $T_{\mathrm{c}}$ of systems with a given nitrile increases with the chain length of the $n$ alkane. Thus, $T_{\mathrm{c}}\left(n_{\mathrm{CN}}=1\right) / \mathrm{K}=350.2$ (hexane) $<358$ (heptane) $<381.7$ (decane) $<398.2$ (dodecane) $<403.7$ (tetradecane). ${ }^{75}$ As in other studies, the $H_{\mathrm{m}}^{\mathrm{E}}$ variation is steeper when replacing methanol by ethanol, than when this alcohol is replaced by 1-propanol. This underlines that interactions between unlike molecules are much important in methanol systems. Accordingly, $T S_{m}^{E}$ is also lower for such solutions (Table 3). (iii) Alcohol-alcohol interactions are more easily broken by nitriles in the case of long chain 1-alkanols, which leads to larger 
$\Delta H_{\mathrm{OH}-\mathrm{OH}}$ term. The increase of the $T S_{\mathrm{m}}^{\mathrm{E}}$ with the alcohol size (Table 3) is consistent with this picture. Therefore, association/solvation effects become weaker with the increasing of the alcohol size, and physical interactions are predominant in systems with long chain 1-alkanols.

\section{$4.3 \quad$ Excess molar volumes}

There is a rather wide database on $V_{\mathrm{m}}^{\mathrm{E}}$ for 1-alkanol + nitrile mixtures. ${ }^{13,66,77-92}$ From its examination (see Figure 6), some general trends can be outlined. (i) $V_{\mathrm{m}}^{\mathrm{E}}$ values are rather low and even negative, while the corresponding $H_{\mathrm{m}}^{\mathrm{E}}$ results are large and positive (Table 2). 1Alkanol + alkanone $^{21}$ or + linear polyether ${ }^{20}$ mixtures behave similarly. Some numerial values follow: $\quad V_{\mathrm{m}}^{\mathrm{E}}\left(n_{\mathrm{CN}}=1\right) / \mathrm{cm}^{3} \cdot \mathrm{mol}^{-1}=-0.145$ (methanol) ${ }^{86}-0.022$ (ethanol); ${ }^{86} 0.098$ (1butanol) $;^{86} 0.194$ (1-hexanol) $;^{86} 0.280$ (1-octanol) $;{ }^{82} 0.340,{ }^{90} 0.378^{86}$ (1-decanol). The $H_{\mathrm{m}}^{\mathrm{E}}$ values are ranged between 1086 (methanol $)^{5}$ and $3032\left(1\right.$-decanol) ${ }^{14} \mathrm{~J} \cdot \mathrm{mol}^{-1}$. This suggests the existence of interactions between unlike molecules and/or structural effects (see below). (ii) Both magnitudes $V_{\mathrm{m}}^{\mathrm{E}}$ and $H_{\mathrm{m}}^{\mathrm{E}}$ of solutions with a given $n_{\mathrm{CN}}$ value increase with $n_{\mathrm{OH}}$. Thus, the $V_{\mathrm{m}}^{\mathrm{E}}$ variation can be essentially attributed to an increased contribution from the breaking of the interactions between like molecules. (iii) For mixtures with $n_{\mathrm{OH}}=1-3, V_{\mathrm{m}}^{\mathrm{E}}\left(n_{\mathrm{CN}}=1\right)<$ $V_{\mathrm{m}}^{\mathrm{E}}\left(n_{\mathrm{CN}}=3\right)$, while an inversion in this variation is produced from $n_{\mathrm{OH}} \geq 4$ (Figure 6). This suggests that the contributions to $V_{\mathrm{m}}^{\mathrm{E}}$ from interactions between unlike molecules and from structural effects are more relevant in systems formed by ethanenitrile and shorter 1-alkanols than in those with butanenitrile. In contrast, for mixtures involving longer 1-alkanols, the interactional contribution to $V_{\mathrm{m}}^{\mathrm{E}}$ from the disruption of interactions between like molecules is more relevant in ethenanitrile solutions. (iv) For $n_{\mathrm{CN}}=1$ and $n_{\mathrm{OH}} \geq 4$, the $V_{\mathrm{m}}^{\mathrm{E}}$ curves are skewed to higher mole fractions of the nitrile, ${ }^{86}$ the smaller compound, which suggests that structural effects are of the free volume type. A similar trend is observed in methanol or ethanol + linear polyether mixtures. ${ }^{93}$ For $n_{\mathrm{OH}}=2,3$, the $V_{\mathrm{m}}^{\mathrm{E}}$ curves are s-shaped, with positive values at lower mole fractions of the alcohol. ${ }^{86}$ This seems to indicate that the alkanol network is better broken in that region. For $n_{\mathrm{OH}}=1, V_{\mathrm{m}}^{\mathrm{E}}$ values are negative at any alcohol composition, ${ }^{86}$ which might be ascribed, at least in part, to the existence of interactions between unlike molecules. However, free volume effects are also present as the $V_{\mathrm{m}}^{\mathrm{E}}$ curve is skewed to higher mole fractions of the alcohol (smaller compound). In the case of solutions with $n_{\mathrm{CN}}=3$ and longer 1- 
alkanols, the $V_{\mathrm{m}}^{\mathrm{E}}$ curves become more symmetrical ${ }^{84}$ as butanenitrile size is larger than that of ethanenitrile. The s-shaped $V_{\mathrm{m}}^{\mathrm{E}}$ curve of the system with $n_{\mathrm{OH}}=1$ can be explained in terms of a lower contribution (in absolute value) to this magnitude from the creation of alcoholnitrile interactions. Interestingly, the $V_{\mathrm{m}}^{\mathrm{E}}$ curves of benzonitrile systems are shifted to lower mole fractions of the nitrile (the larger component) ${ }^{15,88}$ showing, newly, the existence of free volume effects. (v) The magnitude $A_{\mathrm{p}}=\left(\frac{\partial V_{\mathrm{m}}^{\mathrm{E}}}{\partial T}\right)_{\mathrm{p}}$ is positive for mixtures formed by ethanenitrile and $n_{\mathrm{OH}}=1-5,{ }^{78,87}$ and becomes negative for solutions with $n_{\mathrm{OH}}=8,10 .{ }^{90}$ Thus, $A_{\mathrm{p}}\left(n_{\mathrm{CN}}=1\right) / \mathrm{cm}^{3} \cdot \mathrm{mol}^{-1} \cdot \mathrm{K}^{-1}=1.09 \cdot 10^{-3}\left(n_{\mathrm{OH}}=1\right){ }^{.78}-3.8 \cdot 10^{-3}\left(n_{\mathrm{OH}}=10\right) .{ }^{90}$ Positive values of $A_{\mathrm{p}}$ are encountered in solutions where association effects are preponderant; negative $A_{\mathrm{p}}$ values are found in systems where important structural effects exist. For example, $A_{\mathrm{p}}=-1.2 \cdot 10^{-2}$ $\mathrm{cm}^{3} \cdot \mathrm{mol}^{-1} \cdot \mathrm{K}^{-1}$ for the hexadecane + hexane mixture; ${ }^{94}$ and for the 1-propanol + heptane solution, ${ }^{95,96} A_{\mathrm{p}}=5.9 \cdot 10^{-3} \mathrm{~cm}^{3} \cdot \mathrm{mol}^{-1} \cdot \mathrm{K}^{-1}$. The negative $A_{\mathrm{p}}$ value of the methanol + benzonitrile system $\left(-3.8 \cdot 10^{-3} \mathrm{~cm}^{3} \cdot \mathrm{mol}^{-1} \cdot \mathrm{K}^{-188}\right)$ may be interpreted in terms of the existence of relevant structural effects.

\subsection{Results from the Flory model}

We define the mean standard relative deviation of $H_{\mathrm{m}}^{\mathrm{E}}$ as:

$$
\bar{\sigma}_{\mathrm{r}}\left(H_{\mathrm{m}}^{\mathrm{E}}\right)=\frac{1}{N_{\mathrm{S}}} \sum \sigma_{\mathrm{r}}\left(H_{\mathrm{m}}^{\mathrm{E}}\right)
$$

where $N_{\mathrm{S}}$ represents the number of systems considered. At $298.15 \mathrm{~K}, \bar{\sigma}_{\mathrm{r}}\left(H_{\mathrm{m}}^{\mathrm{E}}\right)$ shows close values for $n_{\mathrm{CN}}=1$ or $n_{\mathrm{CN}}=3\left(0.126\left(N_{\mathrm{S}}=6\right)\right.$ and $0.111\left(N_{\mathrm{S}}=10\right)$, respectively $)$. One can conclude that orientational effects are quite similar in both types of mixtures. However, a more detailed examination of results reveals that $\sigma_{\mathrm{r}}\left(H_{\mathrm{m}}^{\mathrm{E}}\right)$ values of the methanol or ethanol + butanenitrile systems are larger than those of the corresponding solutions with ethanenitrile, probably because alcohol self-association plays a more important role in the former mixtures (see below). In contrast, for 1-nonanol or 1-decanol solutions, $\sigma_{\mathrm{r}}\left(H_{\mathrm{m}}^{\mathrm{E}}\right)\left(n_{\mathrm{CN}}=1\right)>\sigma_{\mathrm{r}}\left(H_{\mathrm{m}}^{\mathrm{E}}\right)$ $\left(n_{\mathrm{CN}}=3\right)($ Table 2$)$ as orientational effects are stronger in these ethenenitrile mixtures due to the system temperature is close to the UCST. On the other hand, the rather large $\sigma_{\mathrm{r}}\left(H_{\mathrm{m}}^{\mathrm{E}}\right)$ values of solutions containing benzonitrile indicate that the aromaticity effect leads to strengthened orientational effects. In spite of such results, remarkably $\sigma_{\mathrm{r}}\left(H_{\mathrm{m}}^{\mathrm{E}}\right)$ is lower than 0.10 for many of the systems under study at $298.15 \mathrm{~K}$, which means that the random mixing 
hypothesis is attained in rather large extent (see results, e.g, for ethanol or 1-propanol or 1butanol + ethanenitrile, or + butanenitrile, Table 2). The increase of temperature slightly weakens orientational effects $\left(\bar{\sigma}_{\mathrm{r}}\left(H_{\mathrm{m}}^{\mathrm{E}}\right)=0.108, N_{\mathrm{S}}=6\right.$ for $n_{\mathrm{CN}}=1$, Table 2). Interestingly, $H_{\mathrm{m}}^{\mathrm{E}}$ and $X_{12}$ do not change in line with $n_{\mathrm{OH}}$ for a given $n_{\mathrm{CN}}$ value. In fact, the excess function increases with $n_{\mathrm{OH}}$, while $X_{12}$ increases up to ethanol or 1-propanol and then slowly decreases (Table 2). In the case of $n_{\mathrm{CN}}=3$, the very smooth variation of $X_{12}$ with $n_{\mathrm{OH}}$ from 1-hexanol is remarkable. This suggests that, in the framework of the theory, mixtures with longer 1-alkanols differ mainly by size effects. Thus, the $\sigma_{\mathrm{r}}\left(H_{\mathrm{m}}^{\mathrm{E}}\right)$ value of the 1-decanol + butanenitrile system remains unchanged when is determined using $X_{12}=76.77 \mathrm{~J} \cdot \mathrm{cm}^{-3}$ (the same parameter of the 1hexanol solution). The fact that $H_{\mathrm{m}}^{\mathrm{E}} /\left(x_{1} V_{1}^{*}+x_{2} V_{2}^{*}\right)$, a magnitude widely used to compare $H_{\mathrm{m}}^{\mathrm{E}}$ values of solutions with compounds of very different size, ${ }^{97,98}$ and $X_{12}$ change in line with $n_{\mathrm{OH}}$ (Figure 7) also supports our conclusion. In order to obtain quick $H_{\mathrm{m}}^{\mathrm{E}}$ values for mixtures for which experimental data are not available, one could use $X_{12}=130.71 \mathrm{~J} \cdot \mathrm{cm}^{-3}$ for ethanenitrile solutions with $5 \leq n_{\mathrm{OH}} \leq 8$ and $X_{12}=73.58 \mathrm{~J} \cdot \mathrm{cm}^{-3}$ for butanenitrile systems with $10 \leq n_{\mathrm{OH}} \leq$ 16. Finally, it should be mentioned that the model fails when describing $V_{\mathrm{m}}^{\mathrm{E}}$, as the theoretical results are much higher than the experimental values. The model can not represent the strong structural effects present in these systems.

\section{5 $S_{\mathrm{CC}}(0)$ results}

Inspection of Table 3 shows that 1-alkanol + nitrile systems are characterized by homocoordination $\left(S_{\mathrm{CC}}(0)>0.25\right)$. A comparison of $S_{\mathrm{CC}}(0)$ results for solutions with $n_{\mathrm{CN}}=1$, or 3 becomes difficult as the corresponding $G_{\mathrm{m}}^{\mathrm{E}}$ values are at different temperatures. We have used DISQUAC interaction parameters for the hydroxyl/nitrile contacts obtained by our research group (unpublished results) for calculating $S_{\mathrm{CC}}(0)$ at $298.15 \mathrm{~K}$ for methanol or 1octanol + ethanenitrile systems, and some conclusions can be drawn. (i) The large $S_{\mathrm{CC}}(0)$ value (1.411) for the 1-octanol + ethanenitrile solution is in agreement with the proximity of the system temperature to the critical one (see above), as mixtures at this condition show very large $S_{\text {CC }}(0)$ values. ${ }^{99}$ This is the case, e.g, of pyridine, ${ }^{36}$ nitroethane ${ }^{99}$ or 2 -propanone ${ }^{100}+$ alkane mixtures. (ii) Therefore, homocoordination of systems with e.g. ethanenitrile and long chain 1alkanols is much more relevant than for corresponding solutions with butanenitrile. (iii) In the case of methanol systems, $S_{\mathrm{CC}}(0)\left(n_{\mathrm{CN}}=1\right)<S_{\mathrm{CC}}(0)\left(n_{\mathrm{CN}}=3\right)$, and interactions between 
unlike molecules (i.e., heterocoordination) are more important in the ethanenitrile mixture. Note that, as usually, the increasing of temperature weakens homocoordination.

4.6 Comparison of 1-alkanol + butanenitrile, or + 2-butanone systems

Butanenitrile and 2-butanone are very polar compounds (their dipole moment is 3.50 and $2.76 \mathrm{D}$, respectively ${ }^{101}$ ) of similar size and shape. A comparison of their mixtures with 1alkanols is pertinent. Interestingly, $\Delta H_{\mathrm{OH}-\mathrm{CO}}$ and $\Delta H_{\mathrm{OH}-\mathrm{CN}}$ values are rather similar (Figure 5), while homocoordination is higher in butanenitrile solutions, as 2-butanone mixtures show lower $S_{\mathrm{CC}}(0)$ values $^{21}\left(S_{\mathrm{CC}}(0)=0.425\right.$ (methanol); 0.403 (1-propanol), 0.420 (1-hexanol); 0.443 (1octanol)) (see Table 4 for comparison). The larger $H_{\mathrm{m}}^{\mathrm{E}}$ of systems with butanenitrile could be then explained taking into account that $\Delta H_{\mathrm{CN}-\mathrm{CN}}>\Delta H_{\mathrm{CO}-\mathrm{CO}}$ as $H_{\mathrm{m}, 1}^{\mathrm{E}, \infty} / \mathrm{kJ} \cdot \mathrm{mol}^{-1}=10.2$ $(\text { butanenitrile }+ \text { cyclohexane })^{57}>7.47$ (2-butanone + heptane $)^{102}$ and that heterocoordination is more important in 2-butanone systems. In addition, $T S_{\mathrm{m}}^{\mathrm{E}}(2 \text {-butanone })^{21} / \mathrm{J} \cdot \mathrm{mol}^{-1}=161\left(n_{\mathrm{OH}}=1\right)$; $205\left(n_{\mathrm{OH}}=2\right)$ and $725\left(n_{\mathrm{OH}}=3\right)$, which are lower values than those of systems containing butanenitrile (Table 3). This could be also related to the existence of more interactions between unlike molecules in the alkanone solution. However, an opposite behaviour is observed for mixtures including longer 1-alkanols, e.g, $T S_{\mathrm{m}}^{\mathrm{E}}\left(1\right.$-octanol)/J $\cdot \mathrm{mol}^{-1}=1172$ (2-butanone) ${ }^{21}>1006$ (butanenitrile). ${ }^{82}$ It is remarkable that the same trend is encountered in systems with alkanes. Thus, $T S_{\mathrm{m}}^{\mathrm{E}}$ (heptane) $/ \mathrm{J} \cdot \mathrm{mol}^{-1}=476$ (2-butanone) ${ }^{102,103}>270$ (butanenitrile). ${ }^{104,105}$ An interesting result, as allows to conclude that dipolar interactions become much more important when 2butanone or butanenitrile are mixed with 1-alkanols different to methanol or ethanol than when they are mixed with alkanes. Finally, as an average, orientational effects are very similar in 1alkanol +2 -butanone, or + butanenitrile systems $\left(\bar{\sigma}_{\mathrm{r}}\left(H_{\mathrm{m}}^{\mathrm{E}}\right)=0.111\right)$. However, such effects are more relevant in the methanol +2 -butanone mixture, ${ }^{21}\left(\sigma_{\mathrm{r}}\left(H_{\mathrm{m}}^{\mathrm{E}}\right)=0.270>0.222\right.$ (methanol + butanenitrile)) probably due to the existence of more interactions between unlike molecules. For the remainder solutions, orientational effects seem to be slightly weaker in those including 2butanone: $\bar{\sigma}_{\mathrm{r}}\left(H_{\mathrm{m}}^{\mathrm{E}}\right)=0.079$ (2-butanone) ${ }^{21}<0.099$ (butanenitrile).

\section{Conclusions}

1-Alkanol + alkanenitrile or + benzonitrile mixtures have been investigated through the analysis of $H_{\mathrm{m}}^{\mathrm{E}}, C_{\mathrm{pm}}^{\mathrm{E}}, T S_{\mathrm{m}}^{\mathrm{E}}$ and $V_{\mathrm{m}}^{\mathrm{E}}$ data and using the Flory model and the $S_{\mathrm{CC}}(0)$ formalism. The enthalpy of the hydroxyl-nitrile interactions has been evaluated. These interactions are essentially of dipolar type. Large structural effects are encountered in the studied solutions, as 
their high $H_{\mathrm{m}}^{\mathrm{E}}$ values contrast with low $V_{\mathrm{m}}^{\mathrm{E}}$. Stronger orientational effects are encountered in methanol or 1-nonanol or 1-decanol + ethanenitrile systems, or in methanol or ethanol + butanenitrile mixtures. Aromaticity strengthens orientational effects. For other solutions, the random mixing hypothesis is attained in large extension. $S_{\mathrm{CC}}(0)$ results show that homocoordination is the dominant trend.

\section{References}

1. Le Questel, J.-Y.: Berthelot, M.; Laurence, C. Hydrogen-bond acceptor properties of nitriles: a combined crystallographic and ab initio theoretical investigation. J. Phys. Org. Chem. 2000, 13, 347.

2. Laurence, C.; Brameld, K.A.; Graton, J.; Le Questel, J.-Y.; Renault, E. The pKBHX database: toward a better understanding of hydrogen-bond basicity for medicinal chemists. J. Med. Chem. 2009,52: 4073.

3. Allerhand, A.; Schleyer P. von Rague. Nitriles and isonitriles as proton acceptors in hydrogen bonding: correlation of $\Delta \mathrm{vOH}$ with acceptor structure. J. Am. Chem. Soc. 1963, 85,866 .

4. Gekko, K.; Ohmae, E.; Kameyana, K.; Takagi, T. Acetonitrile-protein interactions: amino acid solubility and preferential solvation. Biochim. Biophys. Acta 1998, 1387, 195.

5. Nagata, I.; Tamura, K. Excess enthalpies of binary and ternary mixtures of acetonitrile with methanol, ethanol and benzene. Fluid Phase Equilib. 1985, 24, 289.

6. Nagata, I.; Tamura, K. Excess molar enthalpies of (propan-1-ol or propan-2-ol + acetonitrile), (propan-1-ol or propan-2-ol + chlorobenzene), and (propan-1-ol or propan2-ol + acetonitrile + chlorobenzene) at 298.15 K. J. Chem. Thermodyn. 1988, $20,87$.

7. Nagata, I.; Tamura, K. Excess molar enthalpies of (butan-1-ol or 2-methylpropan-1-ol + acetonitrile), (2-methylpropan-1-ol + benzene), and (butan-1-ol or 2-methylpropan-1-ol + acetonitrile + benzene) at 298.15 K. J. Chem. Thermodyn. 1988, 20, 1101.

8. Nagata, I. Isothermal vapor-liquid equilibrium of ternary mixtures formed by 1propanol, acetonitrile and benzene. Fluid Phase Equilib. 1985, 24, 279.

9. Nagata, I.; Tamura, K. Isothermal (vapour + liquid) equilibria of (methanol or ethanol + butan-2-ol + acetonitrile + benzene). J. Chem. Thermodyn. 1996, 28, 559.

10. Nagata, I. Isothermal vapor-liquid equilibria for binary and ternary mixtures formed by 1-butanol, acetonitrile and benzene. Thermochim. Acta, 1987, 112, 187.

11. Heintz, A. A new theoretical approach for predicting excess properties of alkanol/alkane mixtures. Ber. Bunsenges. Phys. Chem. 1985, 89, 172. 
12. Treszczanowicz, A.J.; Benson, G.C. Excess volumes of alkanol + alkane binary systems in terms of an association model with a Flory contribution term. Fluid Phase Equilib. 1985, 23, 117.

13. Domanska, U.; Marciniak, M. Experimental (solid-liquid) equilibria and excess molar volumes of alkanol + acetonitrile, propanenitrile, and butanenitrile mixtures. $J$. Chem. Eng. Data 2005, 50, 2035.

14. Francesconi, A.Z.; Lanfredi Viola, D.H. Measurement and correlation of the excess molar enthalpy of (1-nonanol, or 1-decanol + acetonitrile) mixtures at (298.15, 303.15, and 308.15) K and atmospheric pressure. J. Chem. Thermodyn. 2012, 47, 28.

15. Letcher, T.M.; Naicker, P.K. Excess molar enthalpies and excess molar volumes of (an alkanol + nitrile compound) at $T=298.15 \mathrm{~K}$ and $p=0.1 \mathrm{MPa}$. J. Chem. Thermodyn. 2001, 33, 1035.

16. Torres, R.B.; Francesconi, A.Z.; Volpe, P.L.O. Experimental study and modeling using the ERAS-model of the excess molar volume of acetonitrile-alkanol mixtures at different temperatures and atmospheric pressure. Fluid Phase Equilib. 2003, 210, 287.

17. Pina, C.G.; Francesconi, A.Z. New applications of the ERAS model: excess volumes of binary liquid mixtures of 1-alkanols with acetonitrile. Fluid Phase Equilib. 1998, 143, 143.

18. Flory, P.J. Statistical thermodynamics of liquid mixtures. J. Am. Chem. Soc. 1965, 87, 1833.

19. González, J.A.; Riesco, N.; Mozo, I.; García de la Fuente, I.; Cobos, J.C. Application of the Flory theory and of the Kirkwood-Buff formalism to the study of orientational effects in 1-alkanol + linear o cyclic monoether mixtures. Ind. Eng. Chem. Res. 2009, $48,7417$.

20. González, J.A.; Mediavilla, A.; García de la Fuente, I.; Cobos, J.C. Thermodynamics of 1-alkanol + linear polyether mixtures. J. Chem. Thermodyn. 2013, 59, 195.

21. González, J.A.; Mediavilla, A.; García de la Fuente, I.; Cobos, J.C.; Alonso-Tristán, C.; Riesco, N. Orientational effects in 1-alkanol + alkanone mixtures. Ind. Eng. Chem. Res. 2013, 52, 10317.

22. González, J.A.; Riesco, N.; Mozo, I.; García de la Fuente, I.; Cobos, J.C. Thermodynamics of mixtures containing alkoxyethanols. Part XXI. Application of the Flory theory to the study of orientational effects in systems with dibutyl ether or 1butanol. Ind. Eng. Chem. Res. 2007, 46, 1350.

23. González, J.A. Thermodynamics of mixtures containing oxaalkanes. 4. Random mixing and orientational effects in ether + alkane systems. Ind. Eng. Chem. Res. 2010, 49 9511. 
24. González, J.A.; García de la Fuente, I.; Cobos, J.C.; Mozo, I.; Alonso, I. Thermodynamics of mixtures containing oxaalkanes. 6. Random mixing in ether + benzene, or + toluene systems. Thermochim. Acta 2011, 514, 1 .

25. González, J.A.; García de la Fuente, I.; Cobos, J.C.; Riesco, N.; Thermodynamics of mixtures containing oxaalkanes. 7. Random mixing in ether $+\mathrm{CCl}_{4}$ systems. Ind. Eng. Chem. Res. 2012, 51, 5108.

26. Torres, R.B.; Francesconi, A.Z.; Volpe, P.L.O. Thermodynamics of binary mixtures: application of the Prigogine-Flory-Patterson theory to excess molar volumes of acetonitrile + 1-alkanol systems. J. Mol. Liq. 2004, 110, 81 .

27. Van, H.T.; Patterson, D. Volumes of mixing and the $P^{*}$ effect. Part I. Hexan isomers with normal and branched hexadecane. J. Solution Chem., 1982, 11, 793.

28. Landau, L.D.; Lifshitz, E.M. Física Estadística, Reverté, Barcelona, 1969.

29. Cobos, J.C. An exact quasi-chemical equation for excess heat capacity with W-shaped concentration dependence. Fluid Phase Equilib. 1997, 133, 105.

30. Rubio, R.G.; Cáceres, M.; Masegosa, R.M.; Andreoli-Ball, L.; Costas, M.; Patterson, D. Mixtures with W-shape $C_{\mathrm{p}}^{\mathrm{E}}$ curves. A light scattering study. Ber. Bunsenges. Phys. Chem. 1989, 93, 48.

31. Kirkwood, J.G., Buff, F.P. The statistical mechanical theory of solutions. 1. J. Chem. Phys. 1951, 19, 774.

32. Ben-Naim, A. Inversion of the Kirkwood-Buff theory of solutions: application to the water-ethanol system. J. Chem. Phys. 1977, 67, 4884.

33. Bhatia, A.B.; Thornton, D.E. Structural aspects of the electrical resistivity of binary alloys. Phys. Rev. B2 1970, 3004.

34. Ruppersberg, H.; Egger, H. Short-range order in liquid Li-Pb alloy. J. Chem. Phys. 1975, 63, 4095.

35. Gallego, L.J.; López, J.M.; Alonso, J.A. Concentration-dependence of the heat of formation of binary-liquid alloys. Physica $B \& C$ 1983, 122, 23.

36. González, J.A.; Cobos, J.C.; García de la Fuente, I.; Mozo, I. Thermodynamics of mixtures containing amines. IX. Application of the concentration-concentration structure factor to the study of binary mixtures containing pyridines. Thermochim. Acta. 2009, 494, 54.

37. González, J.A.; Mozo, I.; García de la Fuente, I.; Cobos, J.C.; Durov, V.A. Thermodynamics of 1-alkanol + cyclic ether molecules. Fluid Phase Equilib. 2006, 245,168 . 
38. González, J.A.; Mozo, I.; Fernández, M.; García de la Fuente, I.; Cobos, J.C. Thermodynamics of 1-alkanol + aromatic compound mixtures. Systems with dimethylbenzene, ethylbenzene or trimethylbenzene. J. Mol. Liq. 2007, 133, 77.

39. Abe, A.; Flory, P.J. The thermodynamic properties of mixtures of small, nonpolar molecules. J. Am. Chem. Soc. 1965, 87, 1838.

40. Flory, P.J.; Orwoll, R.A.; Vrij, A. Statistical thermodynamics of chain molecule liquids. I. An equation of state for normal paraffin hydrocarbons. J. Am. Chem. Soc. 1964, 86, 3507.

41. Flory, P.J.; Orwoll, R.A.; Vrij, A. Statistical thermodynamics of chain molecule liquids. II. Liquid mixtures of normal paraffin hydrocarbons. J. Am. Chem. Soc. 1964, 86, 3515.

42. Orwoll, R.A.; Flory, P.J. Thermodynamic properties of binary mixtures of $n$-alkanes. $J$. Am. Chem. Soc. 1967, 89, 6822.

43. Howell, P.J.; Skillerne de Bristowe, B.J.; Stubley, D. Enthalpies of mixing of carbon tetrachloride with some methyl-substituted benzenes. Part III. Analysis of the results by use of Flory's theory of liquid mixtures. J. Chem. Soc. A 1971, 397.

44. Allen, G.; Chai, Z.; Chong, C.L.; Higgins, J.S.; Tripathi. J. Thermodynamics of oligomeric binary mixtures of polyethylene glycol and polypropylene glycol methylethers. Polymer 1984, 25, 239.

45. Trejo, L.M.; Costas, M.; Patterson, D. Effect of molecular size on the W-shaped excess heat capacities: oxaalkane-alkane systems. J. Chem. Soc., Faraday Trans. 1991, 87, 3001.

46. Rowlinson, J.S.; Swinton, F.L. Liquids and Liquid Mixtures, Butterworths $3^{\text {th }}$ Ed., London, 1982.

47. Kehiaian, H.V. Studies on liquid-liquid equilibrium. 1. Binary systems with upper and lower critical solubility temperatures. Bull. Acad. Pol. Sci., Ser. Sci. Chim. 1962, 10, 569.

48. Karaoglu, B.; Young, W.H. Conformal mixtures with concentration-dependent interactions. Application to liquid Li-Mg. Phys. Chem, Liq. 1991, 24, 43.

49. Kalali, H.; Kohler, F.; Svejda, P. Excess properties of binary mixtures of 2,2,4trimethylpentane with one polar component. Fluid Phase Equilib. 1985, 20, 75.

50. Diogo, H.P.; Minas de Piedade, M.E.; Moura Ramos, J.; Simoni, J.; Martinho Simoes, J.A. Intermolecular forces in solution and lattice energies of ionic crystals. J. Chem. Educ. 1993, 70, A227

51. Letcher, T.M.; Govender, U.P. Excess molar enthalpies of an alkanol + a cyclic ether at 298.15 K. J. Chem. Eng. Data 1995, 40, 1097.

52. Calvo, E.; Brocos, P.; Piñeiro, A.; Pintos, M.; Amigo, A.; Bravo, R.; Roux, A.H.; Roux.-Desgranges, G. Heat capacities, excess enthalpies, and volumes of binary 
mixtures containing cyclic ethers. 4 . Binary systems 1,4-dioxane +1 -alkanols. $J$. Chem. Eng. Data 1999, 44, 948.

53. González, J.A.; Mozo, I.; García de la Fuente, I.; Cobos, J.C.; Riesco, N. Thermodynamics of (1-alkanol + linear monoether) systems. J. Chem. Thermodyn. 2008, 40, 1495.

54. Letcher, T.M.; Bricknell, B.C. Calorimetric investigation of the interactions of some hydrogen-bonded systems at 298.15 K. J. Chem. Eng. Data 1996, 41, 166.

55. González, J.A.; García de la Fuente, I.; Cobos, J.C. Thermodynamics of mixtures containing oxaalkanes. 5. Ether + benzene, or + toluene systems. Fluid Phase Equilib. 2011, 301, 145 .

56. González, J.A.; Alonso, I.; García de la Fuente, I.; Cobos, J.C. Thermodynamics of ketone + amine mixtures. Part X. Excess molar enthalpies at $298.15 \mathrm{~K}$ for $N, N, N-$ triethylamine +2 -alkanone systems. Characterization of tertiary amine +2 -alkanone, and of amine-ketone $+n$-alkane mixtures in terms of DISQUAC. Fluid Phase Equilib. 2013, 356, 117.

57. Trampe, M.; Eckert, C.A. Calorimetric measurement of partial molar excess enthalpies at infinite dilution. J. Chem. Eng. Data 1991, 36, 112.

58. Brandani, V.; Prausnitz, J.M. A free-volume, non-random mixing theory for liquid mixtures. Fluid Phase Equilib. 1981, 7, 233.

59. Liu, A.; Kohler, F.; Karrer, L.; Gaube, J.; Spelluci, P. A model for the excess properties of 1-alkanol + alkane mixtures containing chemical and physical terms. Pure \& Appl. Chem. 1989, 61, 1441.

60. Renon, H.; Prausnitz, J.M. On the thermodynamics of alcohol-hydrocarbon solutions. Chem. Eng. Sci. 1967, 22, 299.

61. Stokes, R.H.; Burfitt, C. Enthalpies of dilution and transfer of ethanol in non-polar solvents. J. Chem. Thermodyn. 1973, 5, 623.

62. O'Shea, S.J.; Stokes, R.H. Activity coefficients and excess partial molar enthalpies for (ethanol + hexane) from 283 to 318 K. J. Chem. Thermodyn. 1986, 18, 691.

63. Van Ness, H.C.; Van Winkle, J.; Richtol, H.H.; Hollinger, H.B. Infrared spectra and the thermodynamics of alcohol-hydrocarbon systems. J. Phys. Chem. 1967, 71, 1483

64. Sazonov, V.P.; Shaw, D.G. IUPAC-NIST solubility data series. 78. Acetonitrile binary systems. J. Phys. Chem. Ref. Data 2002, 31, 989.

65. Vedernikova, E.V.; Gafurov, M.M.; Ataev, M.B. Estimation of the thermodynamic parameters of hydrogen bonding in alcohol solutions by the method of infrared spectroscopy. Russ. Phys. J. 2011, 53, 843. 
66. Garriga, R.; Sánchez, F.; Pérez, P.; Gracia, M. Vapour pressures at several temperatures $T$ and excess functions at $T=298.15 \mathrm{~K}$ of \{butanenitrile + propan-1-ol or propan-2-ol $\}$. J. Chem. Thermodyn. 1995, $27,887$.

67. Collins, S.G.; Christensen, J.J.; Izatt, R.M.; Hanks, R.W. The excess enthalpies of 10 (n-pentane + an $n$-alkanol) mixtures at 298.15 K. J. Chem. Thermodyn. 1980, 12, 609.

68. Mrazek, R.V.; Van Ness, H.C., Heats of mixing: alcohol-aromatic binary systems at $25^{\circ}, 35^{\circ}$, and $45^{\circ} \mathrm{C}$. AIChE 1960, 7, 190.

69. Helambe, S.N.; Chaudhari, A.; Mehrotra, S.C. Temperature dependent dielectric study of $n$-nitriles in methanol using time domain reflectometry. J. Mol. Liq. 2000, 84, 235.

70. Alonso, V.; González, J.A.; García de la Fuente, I.; Cobos, J.C. Dielectric and refractive index measurements for the systems 1-pentanol + octane, or + dibutyl ether or for dibutyl ether + octane at different temperatures. Thermochim. Acta 2012, 543, 246.

71. El-Hefnawy, M.; Shameshima, K.; Matsushita, T.; Tanaka, R. Apparent dipole moments of 1-alkanols in cyclohexane and $n$-heptane, and excess molar volumes of (1alkanol + cyclohexane, or $n$-heptane) at 298.15 K. J. Solution Chem. 2005, 34, 43.

72. Alonso, V.; González, J.A.; García de la Fuente, I.; Cobos, J.C. Dielectric and refractive index measurements for the systems 1-pentanol $+2,5,8,11,14$ pentaoxapentadecane, or for 2,5,8,11,14-pentaoxapentadecane + octane at (293.15303.15) K. Thermochim. Acta 2013, 551, 70.

73. Tanaka, R.; Toyama, S.; Murakami, S. Heat capacities of $\left\{x \mathrm{C}_{n} \mathrm{H}_{2 n+1} \mathrm{OH}+(1-x) \mathrm{C}_{7} \mathrm{H}_{16}\right\}$ for $n=1$ to 6 at 298.15 K. J. Chem. Thermodyn. 1986, 18, 63 .

74. Wang, L.; Benson, G.C. ; Lu, B.C.-Y. Excess enthalpies of (ethanol + hexane + decane or + dodecane) at the temperature 298.15 K. J. Chem. Thermodyn. 1992, 24, 1135.

75. McLure, L.A.; Rodriguez, A.T.; Ingham, P.A.; Steele, J.F. Phase equilibria for binary $n$ alkanenitrile- $n$-alkane mixtures I. Upper liquid-liquid coexistence temperatures for ethanenitrile, propanenitrile and $n$-butanenitrile with some $\mathrm{C}_{5}-\mathrm{C}_{18} n$-alkanes. Fluid Phase Equilib. 1982, 8, 271.

76. González, J.A.; García de la Fuente, I.; Cobos, J.C.; Casanova, C. A characterization of the aliphatic/hydroxyl interactions using a group contribution model (DISQUAC). Ber. Bunsenges. Phys. Chem. 1991, 95, 1658.

77. Narayanaswamy, G.; Dharmaraju, G.; Raman, G.K. Excess volumes and isentropic compressibilities of acetonitrile $+n$-propanol, $+i$-propanol, $+n$-butanol, $+i$-butanol, and + cyclohexanol. J. Chem. Thermodyn. 1981, 13, 327.

78. Cibulka, I.; Nguyen, V.D.; Holub, R.M. Excess molar volumes of an alkanol + acetonitrile $\}$ at 298.15 and $308.15 \mathrm{~K}$ J. Chem. Thermodyn. 1984, 16, 159.

79. Dewan, R.K.; Mehta, S.K.M. Excess volumes of $n$-octanol + acetonitrile, + butyronitrile, + nitromethane, and + nitroethane. J. Chem. Thermodyn. 1986, 18, 101. 
80. Sandhu, J.S.; Sharma, S.K.; Wadit, R.K. Excess molar volumes of 1-alkanol $\left(\mathrm{C}_{1}-\mathrm{C}_{5}\right)$ binary mixtures with acetonitrile. J. Chem. Eng. Data 1986, 31, 152.

81. Garriga, R.; Putze, I.; Pérez, P.; Gracia, M. Vapour pressures at several temperatures $T$ and excess functions at $T=298.15 \mathrm{~K}$ of $\{$ butanenitrile + ethanol or butan-1-ol $\} . J$. Chem. Thermodyn. 1995, 27, 481.

82. Garriga, R.; Pérez, P.; Gracia, M. Vapour pressures at several temperatures $T$ and excess functions at $T=298.15 \mathrm{~K}$ of $\{$ butanenitrile + hexan-1-ol or octan-1-ol $\}$. J. Chem. Thermodyn. 1995, 27, 1057.

83. Saha, N.; Das, B.; Hazra, D.K. Viscosities and excess molar volumes for acetonitrile + methanol at 298.15, 308.15 and 318.15 K. J. Chem. Eng. Data, 1995, 40, 1264.

84. Garriga, R.; Ilarza, J.; Pérez, P.; Gracia, M. Excess functions at $T=298.15 \mathrm{~K}$ of \{butanenitrile + methanol, + pentan-1-ol, + heptan-1-ol, + nonan-1-ol, or + 1-decan-1ol\}. J. Chem. Thermodyn. 1996, 28, 233.

85. Singh Bakshi, M.; Singh, J.; Kaur, H.; Taufeeq Ahmad, S.; Kaur, G. Thermodynamic behaviour of mixtures. 3. Mixtures of acetonitrile with dimethylacetamide, dimethyl sulfoxide, nitrobenzene and methanol at $25^{\circ} \mathrm{C}$. J. Chem. Eng. Data 1996, 41, 1459.

86. Aznarez, S.R.; Postigo, M.A. Excess molar volumes of binary mixtures of acetonitrile with alkanols at $25^{\circ}$ C. J. Solution Chem. 1998, 27, 1045.

87. Nikam, P.S.; Shirsat, L.N.; Hasan, M. Density and viscosity studies for binary mixtures of acetonitrile with methanol, ethanol, propan-1-ol, propan-2-ol, butan-1-ol, pentan-1ol, and 2-methtylpropan-1-ol at (303.15, 308.15 and 313.15) K. J. Chem. Eng. Data, 1998, 43, 732 .

88. Nikam, P.S.; Jagdale, B.S., Sawant, A.B.; Hasan, M. Densities and viscosities for binary mixtures of benzonitrile with methanol, ethanol, propan-1-ol, butan-1-ol, pentan-1-ol, and 2-methtylpropan-2-ol at (303.15, 308.15 and 313.15) K. J. Chem. Eng. Data, 2000, $45,214$.

89. Grguric, I.; Tasic, A.Z.; Djordjevic, B.D.; Kijevcanin, M.; Serbanovic, S.P. Excess molar volume of the acetonitrile + alcohol systems at 298.15 K. Part I: density measurements for acetonitrile + methanol, + ethanol systems. J. Serb. Chem. Soc. 2002, $67,581$.

90. Ali, A.; Kumar, A.N. Ultrasonic and volumetric studies of molecular interactions in acetonitrile +1 -alkanol $\left(\mathrm{C}_{6}, \mathrm{C}_{8}, \mathrm{C}_{10}\right)$ binary liquid mixtures at different temperatures. $J$. Chin. Chem. Soc. 2004, 51, 477.

91. Tahery, R.; Modarress, H.; Satherley, J. Density and surface tension of binary mixtures of acetonitrile +1 -alkanol at 293.15 K. J. Chem. Eng. Data, 2006, 51, 1039. 
92. Deenadayalu, N.; Bhujrajh P. Excess molar volumes and partial molar volumes for (propionitrile + an alkanol) at $T=298.15 \mathrm{~K}$ and $p=0.1 \mathrm{MPa}$. J. Chem. Thermodyn. 2006, 38, 278.

93. Carmona, F.J.; Arroyo, F.J.; García de la Fuente, I; González, J.A.; Cobos, J.C. Excess molar volumes of methanol or etanol $+n$-polyethers at 298.15 K. Can. J. Chem. 1999, $77,1608$.

94. Bolotnikov, M.F.; Neruchev, Y.A.; Melikhov, Y.F.; Verveyko, V.N.; Verveyko, M.V. Temperature dependence of the speed of sound, densities and isentropic compressibilities of hexane + hexadecane in the range (293.15 to 373.15) K. J. Chem. Eng. Data, 2005, 50, 1095-1098.

95. Treszczanowicz, A.J.; Benson, G. C. Excess volumes for $n$-alkanols $+n$-alkanes. I. Binary mixtures of methanol, ethanol, $n$-propanol and $n$-butanol $+n$-heptane. $J$. Chem. Thermodyn., 1977, 9, 1189.

96. Zielkiewicz, J. Excess molar volumes of (heptane + ethanol + propan-1-ol) at the temperature 313.15 K. J. Chem. Thermodyn., 1993, 25, 1243.

97. Phillippe, R.; Delmas, G.; Hong, P.N. Heat of mixing of trialkylamines: disorder and steric hindrance contributions. Can. J. Chem., 1978, 56, 2856.

98. Phillippe, R.; Delmas, G.; Hong, P.N. Excess heats of tri-n-alkylamines and tetraalky tin compounds in linear and branched alkanes: correlations of molecular orientations and steric hindrance effect. Can. J. Chem., 1979, 57, 517.

99. Saint Victor, M.E.; Patterson, D. The W-shaped concentration dependence of $C_{\mathrm{p}}^{\mathrm{E}}$ and solution non-randomness: systems approaching the UCST. Thermochim. Acta, 1990, 159, 177.

100. Rubio, R.G.; Díez Pascual, A.; Coto, B.; Crespo-Colín, A. Concentration fluctuations and surface adsorption in non-ideal binary mixtures. A light scattering and surface tension study. Phys. Chem. Chem. Phys., 2003, 5, 4864.

101. Riddick, J.A.; Bunger, W.B.; Sakano T.K. Organic solvents. In: A. Weissberger (Ed.), Techniques of Chemistry, Vol. II, Wiley, N.Y., 1986.

102. Kiyohara, O.; Handa, Y.P.; Benson, G.C. Thermodynamic properties of binary mixtures containing ketones. III Excess enthalpies of $n$-alkanes + some aliphatic ketones. $J$. Chem. Thermodyn. 1979, 11, 453.

103. Takeo, M.; Nishii, K.; Nitta, T.; Katayama, T. Isothermal vapor-liquid equilibria for two binary mixtures of heptane with 2-butanone and 4-methyl-2-pentanone measured by a dynamic still with a pressure regulation. Fluid Phase Equilib. 1979, 3, 123.

104. Dernini, S.; Polcaro, A.M.; Marongiu, B.; Porcedda, S. Excess volumes and Gibbs free energies of mixtures containing alkanenitriles. Fluid Phase Equilib. 1993, 87, 163. 
105. Marongiu, B. Porcedda, S. Thermodynamics of binary mixtures containing alkanenitriles. 1. Excess enthalpies of some $n$-alkanenitriles $+n$-alkane or + cyclohexane mixtures. J. Chem. Eng. Data 1990, 35, 172.

106. McLure, I. A.; Arriaga-Colina, J.L. Thermal pressure coefficients of ethanenitrile, and butanenitrile in the region 295-395 K. Int. J. Thermophys., 1984, 5, 291.

107. Cibulka, I.; Takagi, T. $P-\rho-T$ data of liquids: Summarization and evaluation. 8 . Miscellaneous compounds. J. Chem. Eng. Data, 2002, 47, 1037.

108. Dohnal, V.; Vesely, F.; Holub, R.; Pick, J. Liquid-vapor equilibrium. 93. Liquid-vapor equilibrium and heats of mixing in the ethanol + acetonitrile system. Collect. Czech. Chem. Commun., 1982, 3177.

109. Dohnal, V.; Vesely, F.; Vins, J. Liquid-vapor equilibrium. 94. Liquid-vapor equilibrium and heats of mixing in the 1-propanol + acetonitrile system.Collect. Czech. Chem. Commun., 1982, 3188.

110. Tanaka, R.; Murakami, Fujishiro, R. Excess enthalpies of mixing a polar liquid + a nonpolar liquid at 298.15 K. J. Chem. Thermodyn. 1974, 6, 209.

111. Nagata, I.; Katoh, K.; Koyabu, J. Liquid-liquid equilibria for ternary systems containing acetonitrile. Thermochim. Acta, 1981, 47, 225.

112. Wilson, S.R.; Patel, R.B.; Abbott, M.M.; Van Ness, H.C. Excess thermodynamic functions for ternary systems. 4. Total pressure data and $G^{\mathrm{E}}$ for acetonitrile-ethanolwater at $50^{\circ}$ C. J. Chem. Eng. Data, 1979, 24, 130.

113. Muthu, O.; Maher, P.J.; Smith B.D. Vapor-liquid equilibrium for the binary systems propionitrile + ethylbenzene, + ethyl alcohol, and + toluene. J. Chem. Eng. Data, 1980, $25,163$.

114. Ohta, T.; Kinoshita, T.; Nagata, I. Isothermal vapor-liquid equilibria for six binary mixtures. J. Chem. Eng. Data, 1983, 28, 36.

115. Nagata, I. Isothermal vapor-liquid equilibria for binary and terary mixtures formed bu 1-butanol, acetonitrile and benzene. Thermochim. Acta, 1987, 112, 187. 


\section{TABLE 1}

Physical Constants ${ }^{\mathrm{a}}$ and Reduction Parameters for Volume, $V_{\mathrm{i}}^{*}$, and Pressure, $P_{\mathrm{i}}^{*}$, Calculated According to the Flory Theory, for Nitriles Used in this Work

\begin{tabular}{lccccc}
\hline Alkanone & $\begin{array}{c}V_{\mathrm{i}} / \\
\mathrm{cm}^{3} \cdot \mathrm{mol}^{-1}\end{array}$ & $\alpha_{\mathrm{P}} / 10^{-3} \cdot \mathrm{K}^{-1}$ & $\kappa_{\mathrm{T}} / \mathrm{TPa}^{-1}$ & $\begin{array}{c}V_{\mathrm{i}}^{*} / \\
\mathrm{cm}^{3} \cdot \mathrm{mol}^{-1}\end{array}$ & $P_{\mathrm{i}}^{*} / \mathrm{J} \cdot \mathrm{cm}^{-3}$ \\
\hline Ethanenitrile & $52.87^{\mathrm{b}}$ & $1.35^{\mathrm{b}}$ & $1070^{\mathrm{b}}$ & 40.20 & 650.8 \\
Butanenitrile & $87.86^{\mathrm{b}}$ & $1.17^{\mathrm{b}}$ & $991^{\mathrm{c}}$ & 68.56 & 578.1 \\
Benzonitrile & $103.06^{\mathrm{b}}$ & $0.864^{\mathrm{b}}$ & $623^{\mathrm{d}}$ & 84.53 & 615.0 \\
\hline
\end{tabular}

${ }^{a}$ molar volume, $V_{\mathrm{i}}$; isobaric thermal expansion coefficient, $\alpha_{\mathrm{P}}$; isothermal compressibility $\kappa_{\mathrm{T}}$;

${ }^{\mathrm{b}} \operatorname{Ref} 101 ;{ }^{\mathrm{c}}$ calculated using ${ }^{106} \gamma=\frac{\alpha_{\mathrm{p}}}{\kappa_{\mathrm{T}}}=1.18 \mathrm{MPa}^{-1} \cdot \mathrm{K}^{-1} ;{ }^{\mathrm{d}}$ Ref. 107 
TABLE 2

Molar Excess Enthalpies, $H_{m}^{\mathrm{E}}$, Interactional Contribution According to the Flory's Model, $H_{m, \text { int }}^{\mathrm{E}}$ and Flory's Interaction Parameter, $X_{12}$, for 1-Alkanol(1) + Nitrile(2) Systems at Equimolar Composition and Temperature $T$.

\begin{tabular}{|c|c|c|c|c|c|}
\hline 1-alkanol & $T / \mathrm{K}$ & $H_{m}^{\mathrm{E}} / \mathrm{J} \cdot \mathrm{mol}^{-1}$ & $H_{m, \text { int }}^{\mathrm{E}} / \mathrm{J} \cdot \mathrm{mol}^{-1}$ & $X_{12} / \mathrm{J} \cdot \mathrm{cm}^{-3}$ & $\sigma_{r}\left(H_{m}^{E}\right)^{\mathrm{a}}$ \\
\hline \multirow{3}{*}{ Methanol } & & 1-alkanol & + ethanenitrile $(2$ & & \\
\hline & 298.15 & $1086^{5}$ & 765 & 119.23 & 0.147 \\
\hline & 308.15 & $1140^{5}$ & 785 & 124.17 & 0.135 \\
\hline \multirow[t]{3}{*}{ Ethanol } & 298.15 & $1500^{5}$ & 1069 & 128.35 & 0.077 \\
\hline & 308.15 & $1574^{5}$ & 1097 & 133.71 & 0.069 \\
\hline & 318.15 & $1645^{108}$ & 1120 & 138.69 & 0.056 \\
\hline \multirow[t]{3}{*}{ 1-propanol } & 298.15 & $1827^{6}$ & 1326 & 133.41 & 0.075 \\
\hline & 308.15 & $1921^{109}$ & 1366 & 139.39 & 0.071 \\
\hline & 318.15 & $1983^{109}$ & 1381 & 143.00 & 0.076 \\
\hline 1-butanol & 298.15 & $2039^{7}$ & 1504 & 131.76 & 0.094 \\
\hline \multirow[t]{2}{*}{ 1-nonanol } & 298.15 & $2671^{14}$ & 2069 & 120.87 & 0.193 \\
\hline & 308.15 & $3050^{14}$ & 2321 & 137.33 & 0.159 \\
\hline \multirow[t]{2}{*}{ 1-decanol } & 298.15 & $3032^{14}$ & 2356 & 130.71 & 0.169 \\
\hline & 308.15 & $3297^{14}$ & 2521 & 141.53 & 0.193 \\
\hline \multicolumn{6}{|c|}{ 1-alkanol(1) + butanenitrile(2) } \\
\hline Ethanol & 298.15 & $1316^{81}$ & 964 & 95.45 & 0.184 \\
\hline 1-propanol & 298.15 & $1522^{66}$ & 1128 & 92.48 & 0.098 \\
\hline 1-butanol & 298.15 & $1587^{81}$ & 1191 & 84.17 & 0.089 \\
\hline 1-pentanol & 298.15 & $1707^{84}$ & 1295 & 81.27 & 0.065 \\
\hline 1-hexanol & 298.15 & $1762^{82}$ & 1347 & 76.77 & 0.107 \\
\hline 1-heptanol & 298.15 & $1867^{84}$ & 1440 & 75.42 & 0.072 \\
\hline 1-octanol & 298.15 & $1960^{82}$ & 1522 & 74.14 & 0.112 \\
\hline 1-nonanol & 298.15 & $2016^{84}$ & 1572 & 72.01 & 0.083 \\
\hline 1-decanol & 298.15 & $2171^{84}$ & 1700 & 73.58 & 0.081 \\
\hline \multicolumn{6}{|c|}{ 1-alkanol(1) + benzonitrile(2) } \\
\hline Methanol & 298.15 & $976^{15}$ & 766 & 91.35 & 0.294 \\
\hline Ethanol & 298.15 & $1209^{15}$ & 943 & 84.55 & 0.188 \\
\hline 1-propanol & 298.15 & $1454^{15}$ & 1133 & 83.98 & 0.166 \\
\hline
\end{tabular}

${ }^{\mathrm{a}}$ Relative standard deviations for $H_{m}^{\mathrm{E}}($ eq. 8) 


\section{TABLE 3}

Molar Excess Gibbs Energies, $G_{m}^{\mathrm{E}}, T S_{m}^{\mathrm{E}}\left(=H_{m}^{\mathrm{E}}-G_{m}^{\mathrm{E}}\right)$, ${ }^{\mathrm{a}}$ and Concentration-Concentration Structure Factor, $S_{\mathrm{CC}}(0)$, for 1-Alkanol(1) + Nitrile(2) Mixtures at Equimolar Composition and Temperature $T$.

\begin{tabular}{|c|c|c|c|c|}
\hline System & $T / \mathrm{K}$ & $G_{m}^{\mathrm{E}} / \mathrm{J} \cdot \mathrm{mol}^{-1}$ & $T S_{m}^{\mathrm{E}} / \mathrm{J} \cdot \mathrm{mol}^{-1}$ & $S_{\mathrm{CC}}(0)$ \\
\hline \multirow[t]{2}{*}{ Methanol(1) + ethanenitrile(2) } & 298.15 & $668^{\mathrm{b}}$ & 418 & $0.579^{\mathrm{b}}$ \\
\hline & 328.15 & $619^{111}$ & & 0.432 \\
\hline \multirow[t]{3}{*}{ Ethanol(1) + ethanenitrile(2) } & 298.15 & $860^{\mathrm{b}}$ & 640 & $0.793^{\mathrm{b}}$ \\
\hline & 323.15 & $795^{112}$ & & 0.556 \\
\hline & 393.15 & $533^{113}$ & & 0.364 \\
\hline \multirow[t]{2}{*}{ 1-propanol(1) + ethanenitrile(2) } & 298.15 & $956^{\mathrm{b}}$ & 871 & $0.666^{\mathrm{b}}$ \\
\hline & 328.15 & $859^{114}$ & & 0.599 \\
\hline \multirow[t]{2}{*}{ 1-butanol(1) + ethanenitrile(2) } & 298.15 & $1026^{\mathrm{b}}$ & 1013 & $0.808^{\mathrm{b}}$ \\
\hline & 333.15 & $908^{115}$ & & 0.610 \\
\hline 1-octanol(1) + ethanenitrile(2) & 298.15 & $1222^{b}$ & & $1.411^{\mathrm{b}}$ \\
\hline \multirow[t]{3}{*}{ Methanol(1) + butanenitrile(2) } & 278.15 & $759^{84}$ & & 0.600 \\
\hline & 298.15 & $733^{84}$ & 245 & 0.556 \\
\hline & 318.15 & $710^{84}$ & & 0.500 \\
\hline \multirow[t]{3}{*}{ Ethanol(1) + butanenitrile(2) } & 278.15 & $809^{81}$ & & 0.666 \\
\hline & 298.15 & $774^{81}$ & 542 & 0.578 \\
\hline & 323.15 & $733^{81}$ & & 0.502 \\
\hline \multirow[t]{3}{*}{ 1-propanol(1) + butanenitrile(2) } & 278.15 & $839^{66}$ & & 0.516 \\
\hline & 298.15 & $754^{66}$ & 768 & 0.504 \\
\hline & 323.15 & $702^{66}$ & & 0.472 \\
\hline \multirow[t]{3}{*}{ 1-butanol(1) + butanenitrile(2) } & 278.15 & $852^{81}$ & & 0.738 \\
\hline & 298.15 & $787^{81}$ & 800 & 0.605 \\
\hline & 323.15 & $710^{81}$ & & 0.488 \\
\hline 1-pentanol(1) + butanenitrile(2) & 298.15 & $834^{84}$ & 873 & 0.609 \\
\hline 1-hexanol(1) + butanenitrile(2) & 298.15 & $854^{82}$ & 908 & 0.663 \\
\hline 1-heptanol(1) + butanenitrile(2) & 298.15 & $908^{84}$ & 959 & 0.934 \\
\hline 1-octanol(1) + butanenitrile $(2)$ & 298.15 & $954^{82}$ & 1006 & 0.830 \\
\hline 1-decanol(1) + butanenitrile(2) & 298.15 & $1049^{84}$ & 1122 & 0.906 \\
\hline
\end{tabular}

${ }^{\mathrm{a}} T S_{\mathrm{m}}^{\mathrm{E}}$ values calculated using $H_{\mathrm{m}}^{\mathrm{E}}$ data from Table 2 ; ${ }^{\mathrm{b}}$ DISQUAC value 
TABLE 4

Partial Molar Excess Enthalpies, ${ }^{\mathrm{a}} H_{1}^{\mathrm{E}, \infty}$, at $\boldsymbol{T}=\mathbf{2 9 8 . 1 5} \mathrm{K}$ at Atmospheric Pressure for Solute(1) + Organic Solvent(2) Mixtures, and Hydrogen Bond Enthalpies, $\Delta H_{\mathrm{OH}-\mathrm{CN}}$, for 1-Alkanol(1) + Nitrile(2) Systems.

\begin{tabular}{|c|c|c|}
\hline System & $H_{1}^{\mathrm{E}, \infty} / \mathrm{kJ} \cdot \mathrm{mol}^{-1}$ & $\Delta H_{\mathrm{OH}-\mathrm{CN}} / \mathrm{kJ} \cdot \mathrm{mol}^{-1}$ \\
\hline ethanenitrile(1) + cyclohexane(2) & $15.0^{57, \mathrm{a}}$ & \\
\hline butanenitrile $(1)+$ cyclohexane $(2)$ & $10.2^{57, \mathrm{a}}$ & \\
\hline benzonitrile $(1)+$ cyclohexane $(2)$ & $10.43^{110}$ & \\
\hline \multirow[t]{2}{*}{ methanol(1) + ethanenitrile(2) } & $5.66^{57, a}$ & -32.5 \\
\hline & $6.06^{5, \mathrm{~b}}$ & \\
\hline \multirow[t]{2}{*}{ ethanol(1) + ethanenitrile(2) } & $7.88^{57, \mathrm{a}}$ & -30.3 \\
\hline & $7.99^{5, \mathrm{~b}}$ & \\
\hline \multirow[t]{2}{*}{ 1-propanol $(1)+$ ethanenitrile $(2)$} & $8.84^{57, \mathrm{a}}$ & -29.4 \\
\hline & $9.24^{6, \mathrm{~b}}$ & \\
\hline \multirow[t]{2}{*}{ 1-butanol(1) + ethanenitrile(2) } & $10.29^{57, a}$ & -27.9 \\
\hline & $10.39^{7, b}$ & \\
\hline 1-nonanol(1) + ethanenitrile $(2)$ & $15.53^{14, \mathrm{~b}}$ & -22.7 \\
\hline 1-decanol(1) + ethanenitrile(2) & $18.98^{14, \mathrm{~b}}$ & -19.2 \\
\hline methanol(1) + butanenitrile $(2)$ & $4.91^{84, \mathrm{~b}}$ & -28.5 \\
\hline ethanol(1) + butanenitrile(2) & $7.17^{81, \mathrm{~b}}$ & -26.2 \\
\hline 1-propanol(1) + butanenitrile(2) & $8.08^{66, b}$ & -25.3 \\
\hline 1-butanol(1) + butanenitrile(2) & $8.39^{81, \mathrm{~b}}$ & -25.0 \\
\hline 1-pentanol $(1)+$ butanenitrile $(2)$ & $8.32^{84, b}$ & -25.1 \\
\hline 1-hexanol(1) + butanenitrile(2) & $9.89^{82, b}$ & -23.5 \\
\hline 1-heptanol $(1)+$ butanenitrile $(2)$ & $9.86^{84, b}$ & -23.5 \\
\hline 1-octanol $(1)+$ butanenitrile $(2)$ & $12.32^{82, \mathrm{~b}}$ & -21.5 \\
\hline 1-nonanol $(1)+$ butanenitrile $(2)$ & $11.95^{84, \mathrm{~b}}$ & -21.7 \\
\hline 1-decanol(1) + butanenitrile $(2)$ & $11.36^{84, \mathrm{~b}}$ & -22.0 \\
\hline methanol(1) + benzonitrile $(2)$ & $6.50^{15, b}$ & -27.1 \\
\hline ethanol(1) + benzonitrile $(2)$ & $8.23^{15, b}$ & -25.4 \\
\hline 1-propanol(1) + benzonitrile(2) & $9.07^{15, \mathrm{~b}}$ & -24.6 \\
\hline
\end{tabular}

${ }^{\mathrm{a}}$ value obtained from $H_{\mathrm{m}}^{\mathrm{E}}$ data at high dilution; ${ }^{\mathrm{b}}$ value obtained from $H_{\mathrm{m}}^{\mathrm{E}}$ data over the whole concentration range 


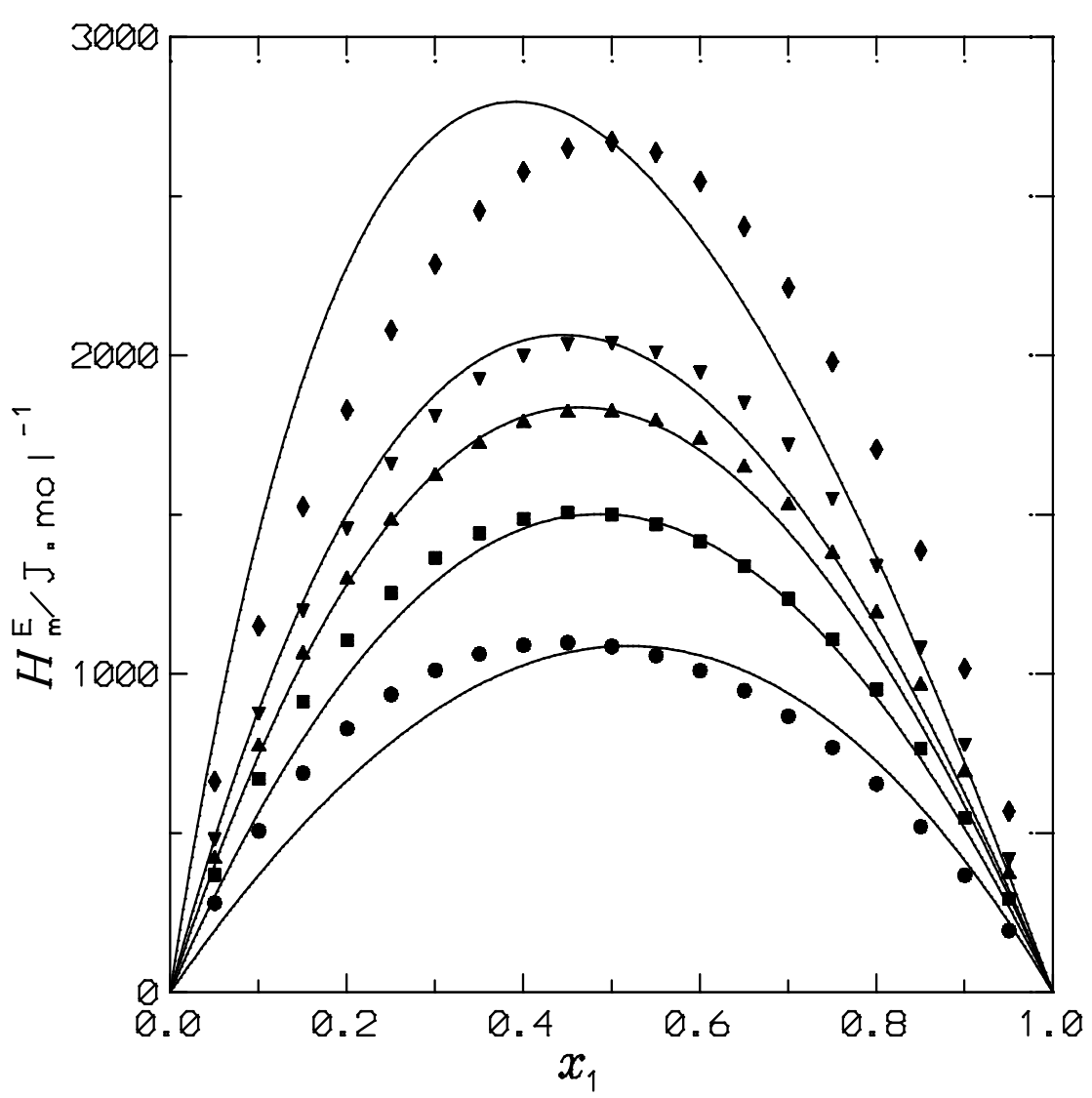

Figure $1 H_{\mathrm{m}}^{\mathrm{E}}$ of 1-alkanol(1) + ethanenitrile(2) systems at $298.15 \mathrm{~K}$. Symbols,

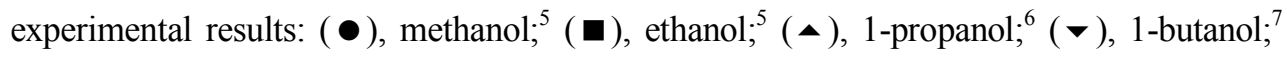
$(\bullet)$, 1-nonanol. ${ }^{14}$ Solid lines, results from the Flory model with interaction parameters listed in Table 2. 


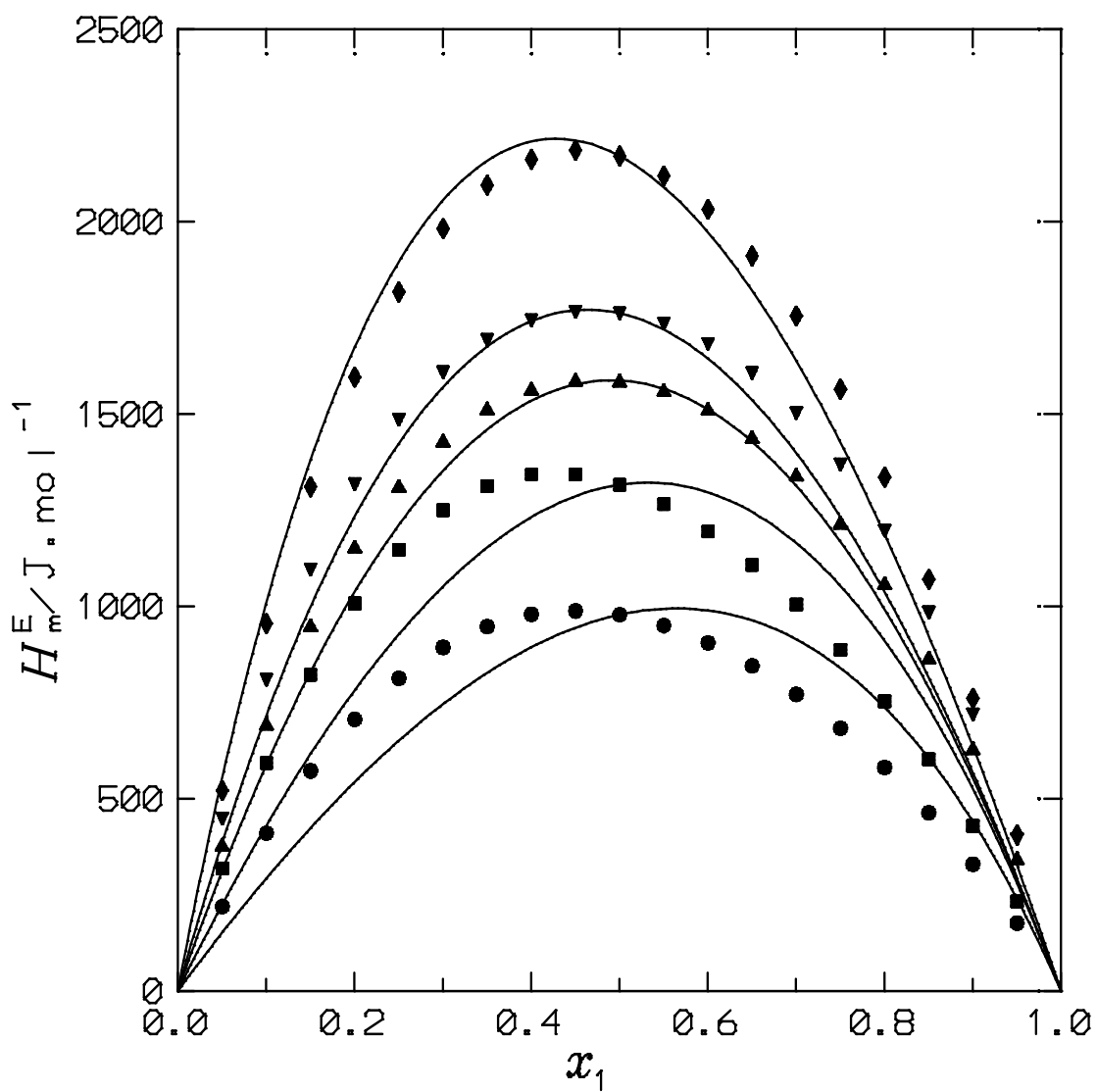

Figure $2 H_{\mathrm{m}}^{\mathrm{E}}$ of 1-alkanol(1) + butanenitrile(2) systems at $298.15 \mathrm{~K}$. Symbols, experimental results: $(\bullet)$, methanol; ${ }^{84}(\boldsymbol{\bullet})$, ethanol; ${ }^{81}(\boldsymbol{\bullet}), 1$-butanol; ${ }^{81}(\bullet), 1$-hexanol, ${ }^{82}$ $(\boldsymbol{\nabla}), 1$-decanol. ${ }^{84}$ Solid lines, results from the Flory model with interaction parameters listed in Table 2. 


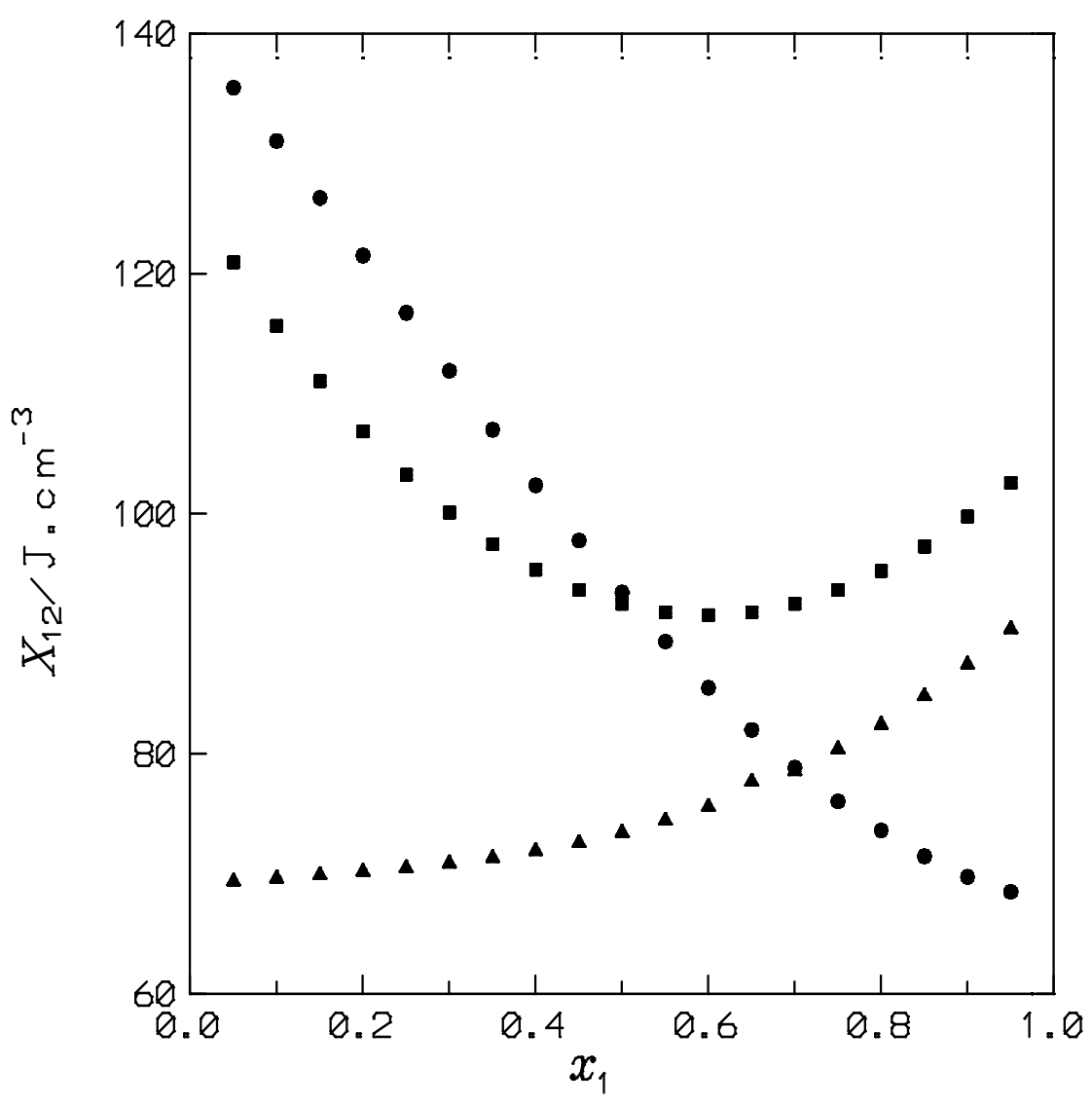

Figu 3 Flory interaction parameters, $X_{12}$, for 1-alkanol(1) + butanenitrile(2) mixtures at

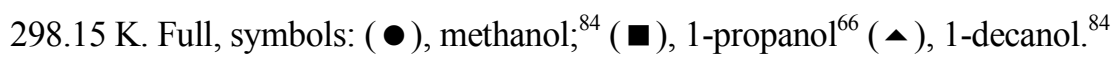


1

2

3

4

5

6

7

8

9

10

11

12

13

14

15

16

17

18

19

20

21

22

23

24

25

26

27

28

29

30

31

32

33

34

35

36

37

38

39

40

41

42

43

44

45

46

47

48

49

50

51

52

53

54

55

56

57

58

59

60

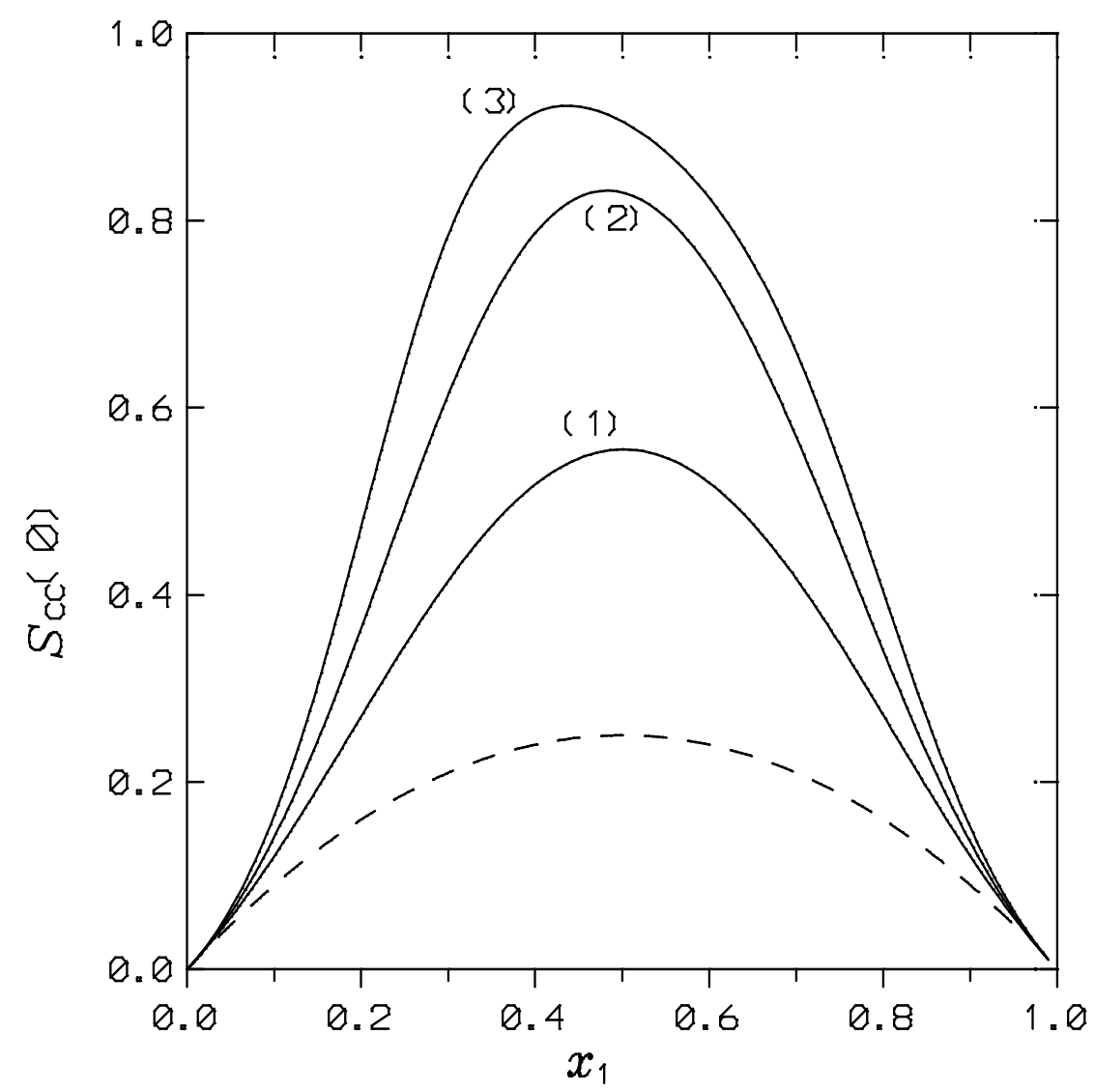

Figure $4 S_{\mathrm{CC}}(0)$ results for 1-alkanol(1) + butanenitrile(2) mixtures at $298.15 \mathrm{~K}$ : (1), methanol $^{84} ;(2), 1$-octanol ${ }^{82} ;(3), 1-$ decanol $^{84}$. Dashed line, ideal mixture 


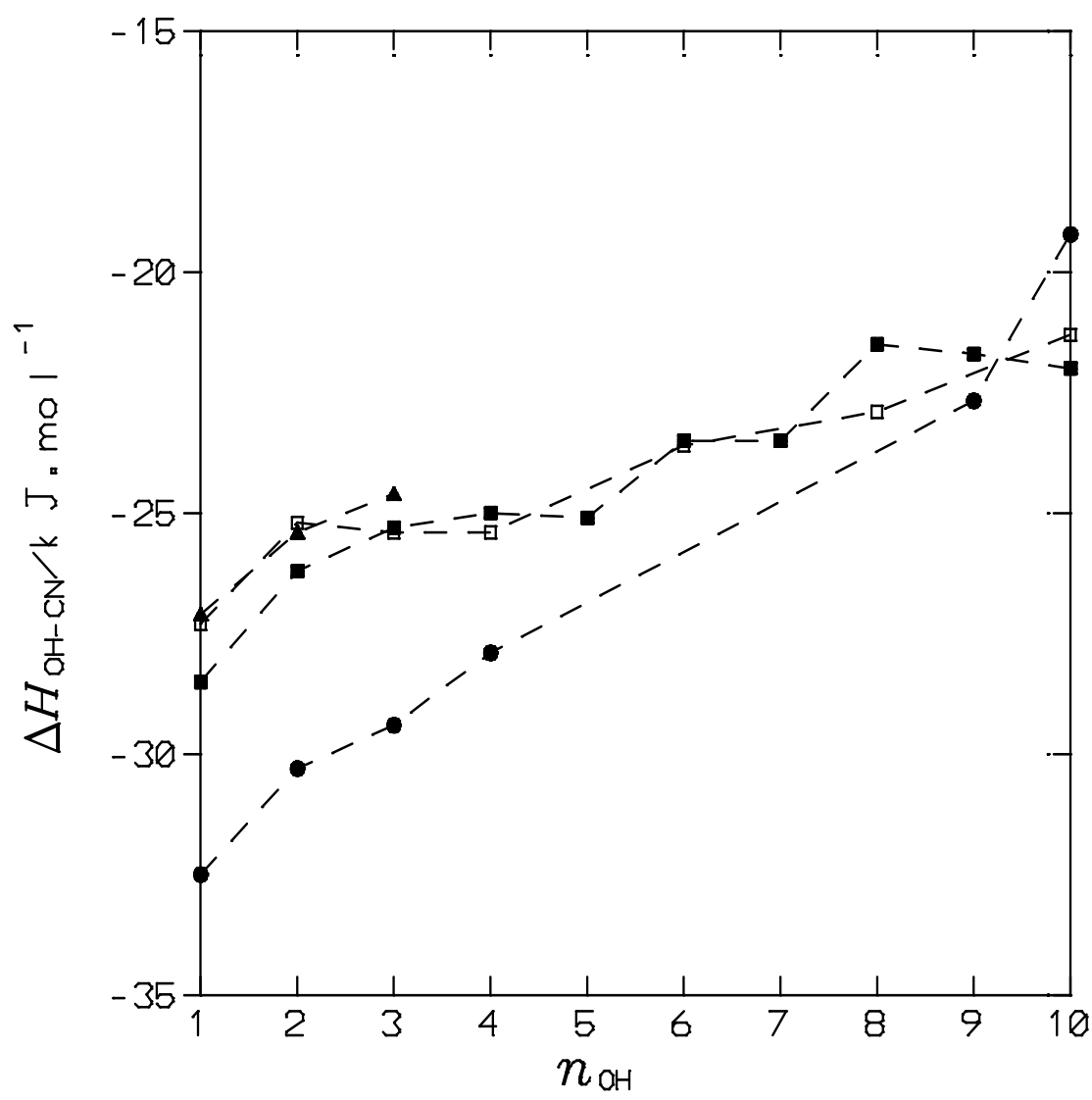

Figure $5 \Delta H_{\mathrm{OH}-\mathrm{CN}}$ of hydroxyl/nitrile interactions in 1-alkanol(1) + nitrile(2) mixtures at 298.15 K. Full symbols, (•), ethanenitrile; ( $\bullet$ ), butanenitrile; ( $\bullet$ ), benzonitrile. Open symbols correspond to the enthalpy of the hydroxyl/carbonyl interactions in 1-alkanol + 2butanone systems. ${ }^{21}$ 
1

2

3

4

5

6

7

8

9

10

11

12

13

14

15

16

17

18

19

20

21

22

23

24

25

26

27

28

29

30

31

32

33

34

35

36

37

38

39

40

41

42

43

44

45

46

47

48

49

50

51

52

53

54

55

56

57

58

59

60

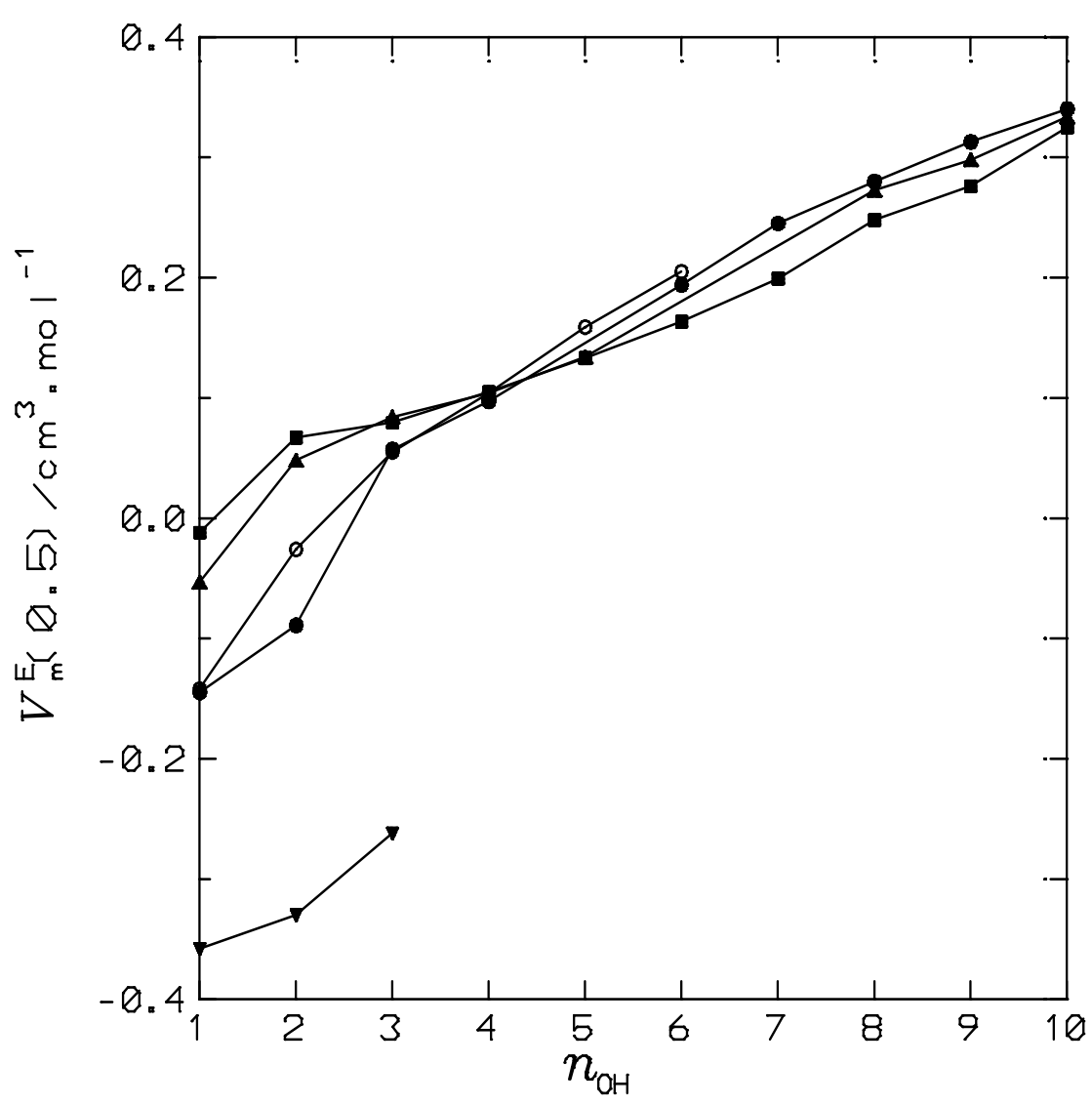

Figure $6 V_{\mathrm{m}}^{\mathrm{E}}$ of 1-alkanol(1) + nitrile(2) systems at $298.15 \mathrm{~K}$. Symbols: experimental results: $(\bullet)$, ethanenitrile; ${ }^{86}(\mathrm{O})$, ethanenitrile ${ }^{78} ;(\bullet)$, propanenitrile; ${ }^{13,92}$ $(\boldsymbol{\square})$, butanenitrile ${ }^{66,81,82,84} ;(\boldsymbol{\nabla})$, benzonitrile. ${ }^{15}$ 


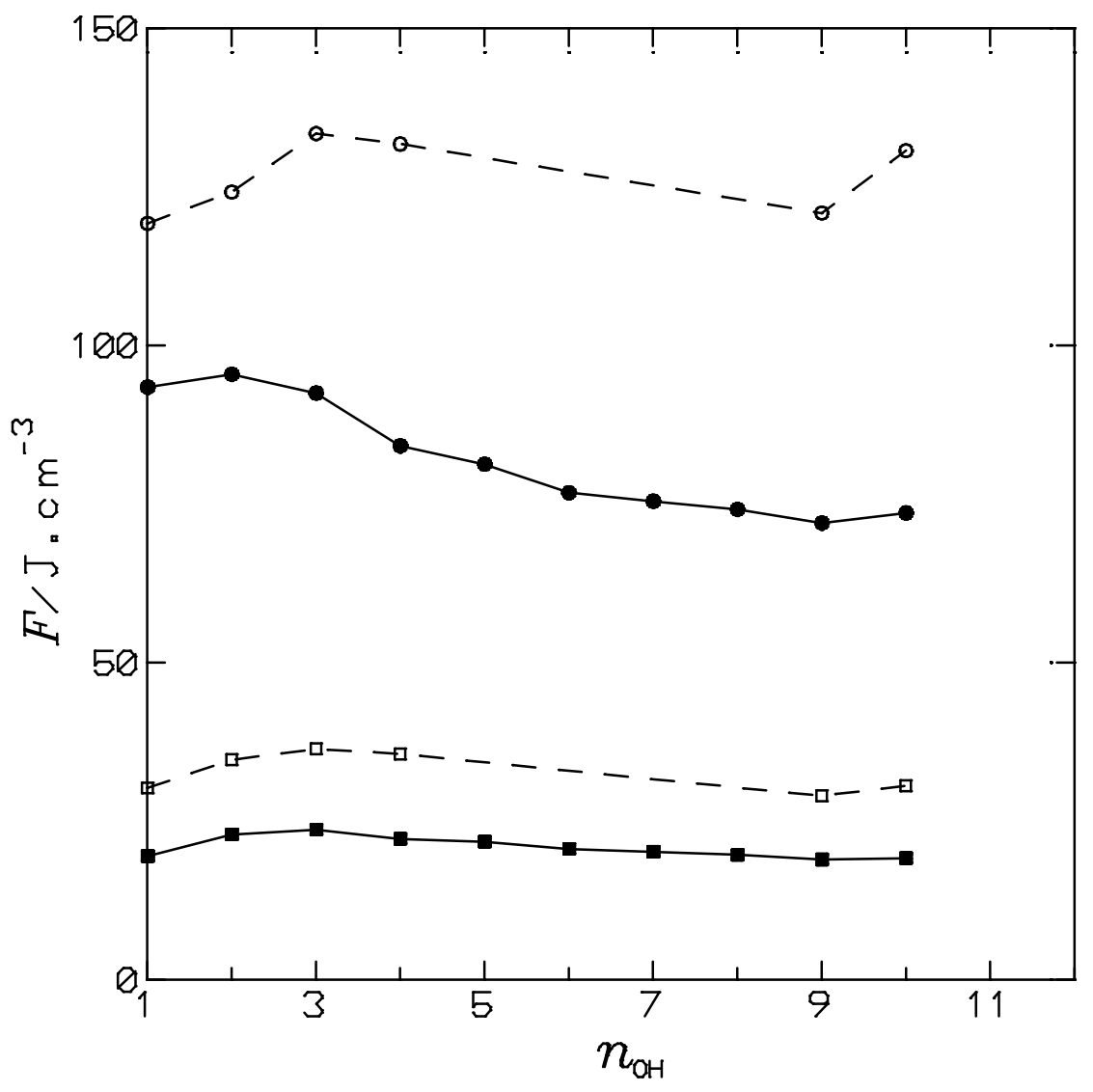

Figure $7 F$ property of 1 -alkanol + nitrile systems at $298.15 \mathrm{~K}$ vs. $n_{\mathrm{OH}}$, the number of $\mathrm{C}$ atoms of the alcohol. $F=X_{12}:(\mathbf{O}), n_{\mathrm{CN}}=1 ;(\bullet), n_{\mathrm{CN}}=3 ; F=H_{\mathrm{m}}^{\mathrm{E}} /\left(x_{1} V_{1}^{*}+x_{2} V_{2}^{*}\right)$ : $\square), n_{\mathrm{CN}}=1 ;(\boldsymbol{\square}), n_{\mathrm{CN}}=3$ 